\title{
Comparison of Interfacial Electron Transfer through Carboxylate and Phosphonate Anchoring Groups ${ }^{\dagger}$
}

\author{
Chunxing She, ${ }^{\ddagger}$ Jianchang Guo, ${ }^{\ddagger}$ Stephan Irle, ${ }^{\ddagger},, \|$ Keiji Morokuma, $, \$,, \|$ Debra L. Mohler, ${ }^{\perp}$ \\ Herve Zabri, ${ }^{\prime}$ Fabrice Odobel, ${ }^{\#}$ Kyoung-Tae Youm, ${ }^{+}$Fang Liu, ${ }^{+}$Joseph T. Hupp, ${ }^{+}$and \\ Tianquan Lian*⿻; \\ Department of Chemistry, Emory University, Atlanta, Georgia 30322, Cherry L. Emerson Center for Scientific \\ Computation, Emory University, Atlanta, Georgia 30322, Fukui Institute for Fundamental Chemistry, Kyoto \\ University, Kyoto 606-8103, Japan, Department of Chemistry, James Madison University, Harrisonburg, \\ Virginia 22807, Laboratoire de Synthèse Organique, UMR 6513, FR-CNRS 2465, Faculté des Sciences et des \\ Techniques de Nantes BP 92208 2, rue de la Houssinière, 44322 NANTES Cedex 3, France, and Department of \\ Chemistry, Northwestern University, Evanston, Illinois 60208
}

Received: February 1, 2007; In Final Form: April 5, 2007

\begin{abstract}
The effects of anchoring groups on electron injection from adsorbate to nanocrystalline thin films were investigated by comparing injection kinetics through carboxylate versus phosphonate groups to $\mathrm{TiO}_{2}$ and $\mathrm{SnO}_{2}$. In the first pair of molecules, $\operatorname{Re}\left(\mathrm{L}_{\mathrm{A}}\right)(\mathrm{CO})_{3} \mathrm{Cl}(\mathrm{ReC} 1 \mathrm{~A})$ and $\mathrm{Re}(\mathrm{Lp})(\mathrm{CO}) 3 \mathrm{Cl}(\operatorname{ReC} 1 \mathrm{P}),\left[\mathrm{L}_{\mathrm{A}}=2,2^{\prime}-\right.$ bipyridine-4,4'-bis- $\mathrm{CH}_{2}-\mathrm{COOH}, \mathrm{Lp}=2,2^{\prime}$-bipyridine-4,4'-bis- $\mathrm{CH}_{2}-\mathrm{PO}_{3} \mathrm{H}_{2}$, the anchoring groups were insulated from the bipyridine ligand by a $\mathrm{CH}_{2}$ group. In the second pair of molecules, $\mathrm{Ru}\left(\mathrm{dcbpyH}_{2}\right)_{2}(\mathrm{NCS})_{2}(\mathrm{RuN} 3)$ and $\mathrm{Ru}\left(\mathrm{bpbpyH}_{2}\right)_{2}(\mathrm{NCS})_{2}(\mathrm{RuN} 3 \mathrm{P})$, [dcbpy $=2,2^{\prime}$-bipyridine-4,4'-biscarboxylic acid, bpbpy $=2,2^{\prime}$-bipyridine$4,4^{\prime}$-bisphosphonic acid], the anchoring groups were directly connected to the bipyridine ligands. The injection kinetics, as measured by subpicosecond IR absorption spectroscopy, showed that electron injection rates from ReC1P to both $\mathrm{TiO}_{2}$ and $\mathrm{SnO}_{2}$ were faster than those from ReC1A. The injection rates from RuN3 and RuN3P to $\mathrm{SnO}_{2}$ films were similar. On $\mathrm{TiO}_{2}$, the injection kinetics from RuN3 and RuN3P were biphasic: carboxylate group enhances the rate of the $<100 \mathrm{fs}$ component, but reduces the rate of the slower components. To provide insight into the effect of the anchoring groups, the electronic structures of $\mathrm{Re}-$ bipyridyl-Ti model clusters containing carboxylate and phosphonate anchoring groups and with and without a $\mathrm{CH}_{2} \mathrm{spacer}$ were computed using density functional theory. With the $\mathrm{CH}_{2}$ spacer, the phosphonate group led to a stronger electronic coupling between bpy and $\mathrm{Ti}$ center than the carboxylate group, which accounted for the faster injection from $\mathrm{ReC} 1 \mathrm{P}$ than $\mathrm{ReC} 1 \mathrm{~A}$. When the anchoring groups were directly connected to the bpy ligand without the $\mathrm{CH}_{2}$ spacer, such as in $\mathrm{RuN} 3$ and $\mathrm{RuN} 3 \mathrm{P}$, their effects were 2-fold: the carboxylate group enhanced the electronic coupling of bpy $\pi^{*}$ with $\mathrm{TiO}_{2}$ and lowered the energy of the bpy orbital. How these competing factors led to different effects on $\mathrm{TiO}_{2}$ and $\mathrm{SnO}_{2}$ and on different components of the biphasic injection kinetics were discussed.
\end{abstract}

\section{Introduction}

The contact between molecular adsorbates and solids has been a subject of intense recent interest because of its importance in many molecule-based devices such as molecular electronics ${ }^{1}$ and dye-sensitized solar cells. ${ }^{2}$ Although it is still poorly understood, the chemical nature of the contact has been shown to play an important role in determining the conductance of the junctions, ${ }^{3-5}$ and rate of interfacial electron transfer. ${ }^{6-9}$ The effect of anchoring group on the efficiency of dye-sensitized solar cells (DSSCs) has also been investigated. So far, the highest solar-to-electric power conversion efficiency $(\sim 11 \%)$ has been obtained in DSSCs based on cis-Ru(dcbpy $)_{2}(\mathrm{NCS})_{2}$

\footnotetext{
$\dagger$ Part of the special issue "M. C. Lin Festschrift".

* Corresponding author.

Department of Chemistry, Emory University.

$\S$ Cherry L. Emerson Center for Scientific Computation, Emory University.

"Kyoto University.

$\perp$ James Madison University.

\# FR-CNRS 2465.

+ Northwestern University.
}

[dcbpy = 2,2'-bipyridine-4,4'-COOH] $(\mathrm{RuN} 3$, see Figure 1) sensitized $\mathrm{TiO}_{2}$ nanocrystalline thin films. ${ }^{2,10}$ These sensitizer molecules are anchored to the $\mathrm{TiO}_{2}$ film through carboxylate $\left(\mathrm{COO}^{-}\right)$groups. The efficiency of cells using cis- $\mathrm{Ru}\left(\mathrm{bpbpyH}_{2}\right)_{2^{-}}$ $(\mathrm{NCS})_{2}$ [bpbpy $=2,2^{\prime}$-bipyridine-4, $\left.4^{\prime}-\mathrm{PO}_{3} \mathrm{H}_{2}\right]$ (RuN3P, see Figure 1) was found to be $30 \%$ less. $^{8}$ In the latter cells, the sensitizer molecules were anchored to $\mathrm{TiO}_{2}$ through the phosphonate $\left(-\mathrm{PO}_{3}{ }^{2-}\right)$ instead of the carboxylate groups, and it is still unclear how the phosphonate anchoring groups lead to the lowering of the cell efficiency. There remain significant interests in designing sensitizers with phosphonate anchoring groups because they have been shown to bind more strongly with metal oxide substrates than carboxylate and are expected to lead to better long-term cell stability. ${ }^{8,11-16}$

The incident photon-to-current conversion efficiency was found to be near unity in RuN3-sensitized $\mathrm{TiO}_{2}$ solar cells, ${ }^{2,10}$ and the high efficiency has been attributed to an ultrafast electron injection and a much slower charge recombination that happens on the microsecond to millisecond time scales. ${ }^{17-19}$ The injection kinetics has been shown to be biphasic, consisting of a primary 


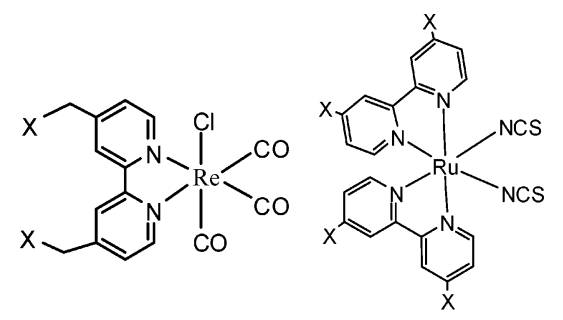

(a)

Figure 1. Schematic structures of (a) $\mathrm{Re}\left(2,2^{\prime}\right.$-bipyridine- $4,4^{\prime}$-bis- $\mathrm{CH}_{2}-$ $\mathrm{X})(\mathrm{CO})_{3} \mathrm{Cl}$ and (b) cis- $\mathrm{Ru}\left(2,2^{\prime} \text {-bipyridine- } 4,4^{\prime} \text {-bis-X }\right)_{2}(\mathrm{NCS})_{2}(\mathrm{X}=$ $\mathrm{COOH}$ or $\mathrm{PO}_{3} \mathrm{H}_{2}$ )

$<100$ fs component and slower components on a few to tens of picosecond time scales. ${ }^{19-33}$ The ultrafast component has been attributed to injection from the unrelaxed singlet metal-to-ligand charge transfer $\left({ }^{1} \mathrm{MLCT}\right)$ state and the slower components to injection from the ${ }^{3}$ MLCT states near the band edge. ${ }^{24,27,31,32,34,35}$ The ultrafast injection process from the unrelaxed excited-state competes with the ultrafast $(\sim 75 \mathrm{fs})^{31,32}$ intramolecular relaxation processes within the dense manifold of excited states. The large amplitude (over 50\%) of the ultrafast ( $<100 \mathrm{fs)}$ component indicates an ultrafast injection rate from the unrelaxed state on the order of $10 \mathrm{~s}$ of femtoseconds or shorter. The ultrafast injection rate in this system has been attributed to the strong electronic coupling between the dcbpy ligand (in RuN3) and $\mathrm{TiO}_{2}{ }^{36}$ It was shown in $\mathrm{Re}(\mathrm{Lc})(\mathrm{CO})_{3} \mathrm{Cl}\left[\mathrm{Lc}=2,2^{\prime}\right.$-bipyridine$\left.4,4^{\prime}-\mathrm{CH}_{2}-\mathrm{COOH}\right](\mathrm{ReC} 1 \mathrm{~A}$, see Figure 1$)$; the insertion of a $\mathrm{CH}_{2}$ group between the bipyridine ligand and the $\mathrm{COOH}$ anchoring group reduces the coupling between the bipyridine ligand and $\mathrm{TiO}_{2}$ such that the ultrafast injection component become negligible. ${ }^{24,37}$ These results suggest that ultrafast electron transfer requires a direct connection of the $\mathrm{COOH}$ anchoring group with the bipyridine ligand. However, it remains unclear how $\mathrm{COOH}$ and other anchoring groups affect the interfacial electron-transfer rate.

In this work the effect of anchoring group on the photoinduced electron injection dynamics from sensitizer molecules to metal oxides nanocrystalline thin films are examined. The carboxylate and phosphonate groups are chosen for this study because they are the most commonly used anchoring groups for binding sensitizers to metal oxide films, ${ }^{8,11-15}$ Electron injection dynamics from $\mathrm{Re}$-bipyridyl and $\mathrm{Ru}$-bipyridyl molecules to $\mathrm{TiO}_{2}$ and $\mathrm{SnO}_{2}$ films are measured by transient IR spectroscopy. In the first pair of molecules, ReC1A and Re$(\mathrm{Lp})(\mathrm{CO}) 3 \mathrm{Cl}(\mathrm{ReC} 1 \mathrm{P}$, see Figure 1) [Lp = 2,2'-bipyridine-4,4'$\left.\mathrm{CH}_{2}-\mathrm{PO}_{3} \mathrm{H}_{2}\right]$, the anchoring groups are insulated from the bipyridine ligand by the $\mathrm{CH}_{2}$ group. In the second pair of molecules, RuN3 and RuN3P, the $\mathrm{COOH}$ and $\mathrm{PO}_{3} \mathrm{H}_{2}$ anchoring groups are directly connected to the bipyridine ligands. The effects of anchoring groups are investigated by comparing injection kinetics in these pairs of molecules. In addition to $\mathrm{TiO}_{2}$, the effects of anchoring groups are also studied on $\mathrm{SnO}_{2}$ nanocrystalline thin films to examine its dependence on the nature of the substrate. It is observed here that electron injection rates from $\mathrm{ReC} 1 \mathrm{P}$ to both $\mathrm{TiO}_{2}$ and $\mathrm{SnO}_{2}$ are faster than those from ReC1A. The injection rates from RuN3 and RuN3P to $\mathrm{SnO}_{2}$ films are similar. On $\mathrm{TiO}_{2}$, the injection kinetics from RuN3 and RuN3P are biphasic, and the anchoring groups have different effects on the ultrafast and slower injection components. With the $\mathrm{PO}_{3}{ }^{2-}$ group, the amplitude of the fast component become smaller, but the rates of the slower components increase. To provide insight into the effect of the anchoring groups, the electronic structures of the $\mathrm{Re}-$ bipyridylTi cluster with different anchoring groups $\left(\mathrm{PO}_{3}{ }^{2-}, \mathrm{COO}^{-}\right)$and

with and without $\mathrm{CH}_{2}$ group are computed using density functional theory (DFT). It is revealed that with the $\mathrm{CH}_{2}$ group, the $\mathrm{PO}_{3}{ }^{2-}$ group enhances the electronic coupling between bpy and $\mathrm{Ti}$ center by providing lower energy LUMO orbitals than the $\mathrm{COO}^{-}$group. Without the $\mathrm{CH}_{2}$ group, the electron density of the pyridine $\pi^{*}$ orbital extends into the $\mathrm{COO}^{-}$group but not the $\mathrm{PO}_{3}{ }^{2-}$ group. The $\mathrm{COO}^{-}$anchoring groups leads to a significant lowering of the energy of bpy $\pi^{*}$ orbital and much stronger electronic coupling with the Ti center. How these electronic effects of the anchoring group affect the electrontransfer rate will be discussed.

\section{Experimental and Computational Methods}

Femtosecond IR Spectrometer. The femtosecond IR spectrometer used in these experiments was based on an amplified femtosecond Ti:sapphire laser system (coherent Vitesse oscillator, Clark-MXR CPA 1000 amplifier, $1 \mathrm{kHz}$ repetition rate at $800 \mathrm{~nm}, 100 \mathrm{fs}$ pulse-width, $900 \mu \mathrm{J} /$ pulse), which has been described in details previously. ${ }^{24,38,39}$ In all the experiments presented here, a sample (of nanocrystalline thin films) was pumped using $400 \mathrm{~nm}$ pulses, and the subsequent absorbance change was measured in the 2000-2150 (for ReC1A and $\mathrm{ReC} 1 \mathrm{P}$ ) or the $2070-2220 \mathrm{~cm}^{-1}$ (for RuN3 and RuN3P) region. Transient kinetics traces at 32 probe wavelengths were collected simultaneously, from which transient spectra at different delay times were constructed. The diameters of the pump and probe beams at the samples were 400 and $300 \mu \mathrm{m}$, respectively. The instrument response function, i.e., the cross-correlation of the pump and probe pulses, was measured in a thin CdS film, in which $400 \mathrm{~nm}$ excitation led to instantaneous generation of free carriers that strongly absorbed in the mid-infrared region. The typical instrument response was well represented by a Gaussian function with a full-width-at-the-half-maximum (fwhm) of less than 200 fs.

Sample Preparations. $\mathrm{TiO}_{2}$ nanoparticle thin films were prepared following a published procedure. ${ }^{40}$ In short, $\mathrm{TiO}_{2}$ nanoparticle colloid was prepared by a controlled hydrolysis of titanium(IV) isopropoxide in a mixture of glacial acetic acid and water at $0{ }^{\circ} \mathrm{C}$. The resulting solution was concentrated at $80{ }^{\circ} \mathrm{C}$, autoclaved at $230{ }^{\circ} \mathrm{C}$ for $12 \mathrm{~h}$, and then stirred for 4 days. A detergent (Triton $\mathrm{X}-100$, Aldrich) was added to the colloid, and it was further stirred for $5 \mathrm{~h}$. The resulting suspension was spread onto polished sapphire windows, and baked at $400{ }^{\circ} \mathrm{C}$ for $1 \mathrm{~h}$.

$\mathrm{SnO}_{2}$ nanoparticle thin films were prepared by using colloidal $\mathrm{SnO}_{2}$ synthesized according to a published procedure. ${ }^{41}$ In short, $\mathrm{SnCl}_{4}$ was dissolved in $\mathrm{HCl}$ and then added dropwise into deionized water under vigorous stirring at $0{ }^{\circ} \mathrm{C}$. The $\mathrm{pH}$ of resulting solution was adjusted to $3.5-4.0$ to obtain $\mathrm{SnO}_{2}$ nanoparticle precipitate. The precipitate was washed and suspended in water by adjusting $\mathrm{pH}$ to $9.5-10$ before dialyzing at $\mathrm{pH} 10$ to produce $\mathrm{SnO}_{2}$ colloidal solution. The $\mathrm{SnO}_{2}$ solution was refluxed and then heated in an autoclave at $150{ }^{\circ} \mathrm{C}$ for $1 \mathrm{~h}$ and at $270{ }^{\circ} \mathrm{C}$ for $16 \mathrm{~h}$. The colloid was then concentrated and mixed with Triton X-100 before casting onto sapphire windows. After drying in air, the samples were baked at $400{ }^{\circ} \mathrm{C}$ for $1 \mathrm{~h}$ to produce nanoporous crystalline thin films.

RuN3 was used as received from Solaronix (Lausanne, Switzerland). RuN3P, ${ }^{8}$ ReC1A, ${ }^{42}$ and $\mathrm{ReC} 1 \mathrm{P}^{43,44}$ were synthesized according to the published procedures. Dye sensitized films were prepared by immersing the films in the dye/solvent solution at room temperature (unless specified). RuN3 samples were sensitized in RuN3/ethanol solution for a few minutes. RuN3P samples were sensitized in solutions of RuN3P in water- 
methanol (1:4) mixture for a few hours at $60-70{ }^{\circ} \mathrm{C}$. ReC1P and $\mathrm{ReC} 1 \mathrm{~A}$ samples were sensitized in $\mathrm{CH}_{3} \mathrm{OH}$ and $\mathrm{C}_{2} \mathrm{H}_{5} \mathrm{OH}$ solutions for $4 \mathrm{~h}$. The films were then washed by appropriate solvents (the same as those used in the sensitizer solutions) and dried in air. Optical densities (O.D.) of the adsorbed dyes on films were controlled by changing the immersing time and concentrations of the dyes. The samples were exposed to air during measurement. The sample cells were scanned rapidly during measurements to prevent any long-term photoproduct build-up. The integrity of the samples was checked by UVvis (Cary 50 Bio UV-visible spectrophotometer) and FTIR spectra (Nicolet Instruments) recorded before and after the transient absorption measurement, which showed negligible changes of the samples after the measurements.

Computational Details. Model Systems. To provide insights into the effect of the anchoring groups on the interaction between the adsorbate and the nanoparticle, electronic structures of simple model systems containing one Ti (IV) center, one anchoring group, and one Re bipyridyl complex were studied. We designed four model systems that reflect that basic ingredients of the experimental compounds. These are $\operatorname{Re}(\mathbf{R} 1 \mathbf{X}$ bpy) $\mathrm{L}^{\prime}$ and $\operatorname{Re}\left(\mathbf{R} 0 \mathbf{X}\right.$-bpy) $\mathrm{L}^{\prime}$, where $\mathrm{L}^{\prime}=(\mathrm{CO})_{3}(\mathrm{Cl})$ and $\mathbf{R} \mathbf{1 X}$ and $\mathbf{R O X}$ denote $-\mathrm{CH}_{2}$-containing and $-\mathrm{CH}_{2}$-free anchoring groups, respectively, attached to a model $\mathrm{TiO}_{2}$ center as specified in the following. $\mathbf{R 1 X}$ is $-\mathrm{CH}_{2}-\mathrm{X}-\mathrm{TiL}$ which consists of different anchoring groups $\mathrm{X}$ : phosphonate $\left(\mathrm{X}=\mathrm{PO}_{3}{ }^{2-}\right.$, denoted $\mathbf{P})$ and carboxylate $\left(\mathrm{X}=\mathrm{COO}^{-}\right.$, denoted $\left.\mathbf{A}\right)$. On the other hand, $\mathbf{R 0 X}$ is $-\mathrm{X}-\mathrm{TiL}$ without the $-\mathrm{CH}_{2}-$ spacer but otherwise identical chemical composition. To maintain charge neutrality of the entire complex and a 6-fold coordination of $\mathrm{Ti}$ by $\mathrm{O}$, $\mathrm{L}$ was chosen as follows: $\mathrm{L}=\left(\mathrm{OH}^{-}\right)_{2} \mathrm{H}_{2} \mathrm{O}$ for $\mathbf{P}$, and $\mathrm{L}$ $=\left(\mathrm{OH}^{-}\right)_{3} \mathrm{H}_{2} \mathrm{O}$ for $\mathbf{A}$. The monodentate model compounds were chosen because we observed the presence of artificial hydrogenbonds between $\mathrm{OH}_{x}$ ligands on both Ti centers when bidentate model compounds were employed. For further analysis simplified $\mathbf{R} \mathbf{1 X}-\mathbf{H}$ compounds that lack bpy and Re units were also investigated; they are comprised of the simple methyl analogs $\mathrm{H}-\mathrm{CH}_{2}-\mathrm{X}-\mathrm{TiL}$ to isolate and identify the influence of the bpy- $\operatorname{Re}(\mathrm{CO})_{3}(\mathrm{Cl})$ group. All of the systems described above possess closed-shell singlet electronic ground states. The electronic structures of "naked" monoanions (R1X-bpy, and ROX-bpy) of corresponding complexes without the $\operatorname{Re}(\mathrm{CO})_{3}$ (Cl) ligand, which mimics the donor state of the $\pi$-conjugated system after electronic excitation to the lowest excited $\pi^{*}$ state, were also investigated. The latter systems possess open-shell doublet electronic ground states. Their geometries were taken from the complexes with the $\operatorname{Re}(\mathrm{CO})_{3}(\mathrm{Cl})$ ligand without reoptimization.

Computational Methodology. Standard density functional theory (DFT) B3LYP/Lanl2DZ as implemented in GAUSSIAN $03 \mathrm{D} 1$, with extra $d$-functions for the third-row $\mathrm{P}$ atom (d-exponent: 0.55$)$, was employed in this study. ${ }^{45}$ Geometry optimization was carried out using redundant internal coordinates and applying the default convergence criteria in GAUSSIAN. Time-dependent DFT (TD-DFT) calculations were carried out on the five lowest excited singlet states following the implementation in GAUSSIAN. Spin-restricted closed-shell RHF-type wavefunctions were employed for Recomplexes, and spin-unrestricted open-shell UHF-type wavefunctions were used for the Re-free anionic model systems.

\section{Results}

1. ReC1A and ReC1P on $\mathrm{TiO}_{2}$. The UV-visible absorption spectra of $\mathrm{ReC} 1 \mathrm{~A}$ and $\mathrm{ReC} 1 \mathrm{P}$ on $\mathrm{TiO}_{2}$ and $\mathrm{SnO}_{2}$ have been

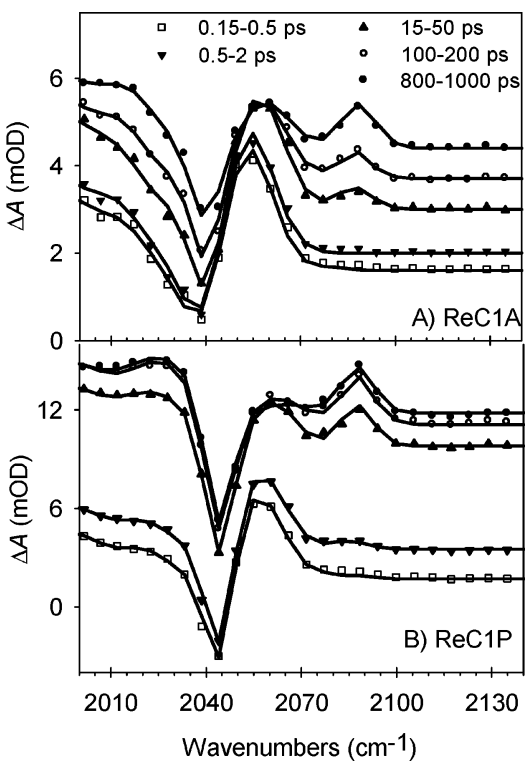

Figure 2. Transient IR absorption spectra of (A) $\mathrm{ReC} 1 \mathrm{~A} / \mathrm{TiO}_{2}$ and (B) $\mathrm{ReC} 1 \mathrm{P} / \mathrm{TiO}_{2}$ in ambient condition (dry) after $400 \mathrm{~nm}$ excitation The symbols are experimental data and lines are fits.

shown previously. ${ }^{9}$ Both complexes showed metal-to-ligand charge transfer (MLCT) transitions centered at $\sim 360 \mathrm{~nm}$ in methanol solution. Similar MLCT bands were observed on $\mathrm{TiO}_{2}$ and $\mathrm{SnO}_{2}$ films. The band center for ReC1P on $\mathrm{SnO}_{2}$ was found to be independent of $\mathrm{pH}$ from 2 to 9 . Similar peak positions for the MLCT band in these complexes indicate that the anchoring groups $\left(\mathrm{COOH}\right.$ and $\mathrm{PO}(\mathrm{OH})_{2}$ does not significantly affect the electronic structure of the bipyridine and the Re orbitals involved in the transition. The lack of sensitivity of MLCT bands to the identity of the anchoring groups and their $\mathrm{pH}$ environments suggest that the bipyridine ligand is insulated from the anchoring group by the $\mathrm{CH}_{2}$ spacer.

The transient IR spectra of $\mathrm{ReC} 1 \mathrm{~A} / \mathrm{TiO}_{2}$ and $\mathrm{ReC} 1 \mathrm{P} / \mathrm{TiO}_{2}$ in ambient environment (exposed to air) after $400 \mathrm{~nm}$ excitation are shown in Figure 2. The spectra at early delay times $(<0.5$ ps) consist of a bleach of ground state $\mathrm{CO}$ stretching band at $\sim 2040 \mathrm{~cm}^{-1}$ and the corresponding excited-state peak at $\sim 2060$ $\mathrm{cm}^{-1}$, similar to the spectra of the same systems measured in pH buffers. ${ }^{9}$ The spectra at later delay times show two additional features: the oxidized peak at $\sim 2090 \mathrm{~cm}^{-1}$ and a broad absorption of injected electrons. The latter leads to a uniform increase of absorbance in the whole spectra range. ${ }^{37,38,42}$ Both the electron absorption and the oxidized-state peak amplitudes increase with delay time, while the excited-state peak amplitude decreases with delay time, indicating electron injection from the excited-state of ReC1A (or ReC1P) into $\mathrm{TiO}_{2}$. The bleach amplitude remains constant in the $<1 \mathrm{~ns}$ time window, suggesting negligible reformation of the ground state by excitedstate decay or by back electron transfer. A comparison of the ratio of the peak amplitudes of the excited and oxidized states at $800-1000$ ps suggests that more molecules in the excitedstate have converted to the oxidized form for ReC1P than $\mathrm{ReC} 1 \mathrm{~A}$, indicating faster electron injection in the former. Negligible oxidized peak amplitude was observed at $<200 \mathrm{fs}$, indicating a lack of instantaneous injection component that was observed for RuN3 and derivatives on $\mathrm{TiO}_{2} \cdot{ }^{19,23-27,31,32}$ This has been attributed to the insertion of $\mathrm{CH}_{2}$ spacer between the bipyridine and the anchoring group, which reduces its electronic coupling with $\mathrm{TiO}_{2}$, slowing down electron injection rate. ${ }^{37}$

The injection rate can be better quantified by comparing injection kinetics in these systems. In Figure 2, the electron 
TABLE 1: Parameters for Multiexponential Fits to and Half-Fise Times of the Electron Injection Kinetics from ReC1A and ReC1P to $\mathrm{TiO}_{2}$ and $\mathrm{SnO}_{2}{ }^{a}$

\begin{tabular}{|c|c|c|c|c|}
\hline \multirow{2}{*}{$\frac{\text { semiconductor }}{\text { sensitizer }}$} & \multicolumn{2}{|c|}{$\mathrm{TiO}_{2}$} & \multicolumn{2}{|c|}{$\mathrm{SnO}_{2}$} \\
\hline & $\mathrm{ReC} 1 \mathrm{P}$ & $\mathrm{ReC} 1 \mathrm{~A}$ & $\mathrm{ReC} 1 \mathrm{P}$ & $\mathrm{ReC} 1 \mathrm{~A}$ \\
\hline$\tau_{1} / \mathrm{ps}\left(A_{1}\right)$ & $1.5(20)$ & $11(19)$ & $2.2(57)$ & $3.8(70)$ \\
\hline$\tau_{2} / \mathrm{ps}\left(A_{2}\right)$ & $14(50)$ & $170(30)$ & $15.6(43)$ & $128(30)$ \\
\hline$\tau_{3} / \mathrm{ps}\left(A_{3}\right)$ & $117(30)$ & $\gg 1 \mathrm{~ns}(51)$ & N/A & N/A \\
\hline$\tau_{\text {ave }}(\mathrm{ps})$ & 38 & N/A & 8 & 41 \\
\hline$\tau_{1 / 2}(\mathrm{ps})$ & 9.3 & 430 & 2.8 & 10 \\
\hline$\tau_{\text {rel }}$ & 1 & 46 & 1 & 3.6 \\
\hline
\end{tabular}

${ }^{a} \tau_{n}$ and $\mathrm{A}_{n}$ (in percentage) are the lifetime and amplitude, respectively, of the $n$th exponential component. $\tau_{\text {ave }}$ is the amplitude-weighted average lifetime. Half-rise time, $\tau_{1 / 2}$, is defined as the time of $50 \%$ injection yield. $\tau_{\text {rel }}$ is the relative value of half-rise time.

injection kinetics from $\mathrm{ReC} 1 \mathrm{P}$ and $\mathrm{ReC} 1 \mathrm{~A}$ to $\mathrm{TiO}_{2}$ films in ambient condition are compared. The kinetics traces are obtained by monitoring the absorbance change of injected electrons in the $\sim 2130 \mathrm{~cm}^{-1}$, at which there is negligible contribution from adsorbate vibrational modes. It was shown previously that the growth kinetics of electron signal and oxidized adsorbate peak agree well each other, so either one can be used to monitor the injection kinetics. ${ }^{9,24,37}$ It indicates that there is negligible contribution of hot injected electrons, which is evident by the lack of instantaneous injection component in the spectra and kinetics traces. The signal size for the two samples has been normalized by the OD of the sample at $400 \mathrm{~nm}$ to correspond to the same number of absorbed photons. For $\mathrm{ReC} 1 \mathrm{P} / \mathrm{TiO}_{2}$, the signal size reaches its maximum value by $\sim 800 \mathrm{ps,} \mathrm{suggesting}$ complete electron injection in those timescales. This is supported by the complete disappearance of the excited-state peak at 800ps shown in Figure 2B. For $\mathrm{ReC} 1 \mathrm{~A} / \mathrm{TiO}_{2}$, the signal size reaches only $\sim 50 \%$ of unity by $\sim 1 \mathrm{~ns}$, consistent with transient spectrum shown in Figure 2A., which indicates that the large amount of the excited-state peak population remains at 800ps.

The injection kinetics can be well fitted by three exponential rise functions. The fitting parameters are summarized in Table 1. One way to compare multiexponential functions is to define an amplitude-weighted-average-time constants $\left(\tau_{\text {ave }}\right)$ :

$$
\tau_{\mathrm{ave}}=\frac{\sum_{i} A_{i} \tau_{i}}{\sum_{i} A_{i}}
$$

$\tau_{\text {ave }}$ is sensitive to the slowest time constants. Unfortunately, for $\mathrm{ReC} 1 \mathrm{~A} / \mathrm{TiO}_{2}$, the injection is not complete within $1 \mathrm{~ns}$ and the time constant for the slowest component is not determined in our measurement. So $\tau_{\text {ave }}$ is not a very good way to characterize the injection kinetics whenever the injection process is incomplete within $1 \mathrm{~ns}$. The half rise time, defined as the time when the injection yield reaches $50 \%$, can be more reliably determined. While value of the half rise time is different from the amplitude weighted average time constants, it will be shown later, the relative injection rate determined from them are in reasonable agreement with each other. The electron injection half rise time for $\mathrm{ReC} 1 \mathrm{~A}$ is $\sim 50$ slower than $\mathrm{ReC} 1 \mathrm{P}$. It was shown previously for $\mathrm{TiO}_{2}$ films in $\mathrm{pH}$ buffers (from 2 to 8) the injection half rise times from $\mathrm{ReC} 1 \mathrm{~A}$ are on average 10 times slower than from ReC1P. ${ }^{9}$

2. ReC1A and ReC1P on $\mathrm{SnO}_{2}$. The comparison of injection rate from $\mathrm{ReC} 1 \mathrm{~A}$ and $\mathrm{ReC} 1 \mathrm{P}$ to $\mathrm{TiO}_{2}$ indicates a clear anchoring group dependence. It is unclear how the anchoring group effect depends on the nature of the semiconductor. To address this

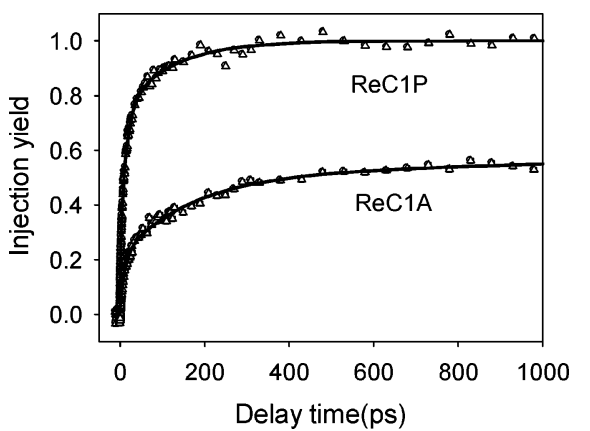

Figure 3. Electron injection kinetics of ReC1P (square) and ReC1A (triangle) sensitized $\mathrm{TiO}_{2}$ in ambient environment probed at $2130 \mathrm{~cm}^{-1}$ after $400 \mathrm{~nm}$ excitation. The symbols are experimental data and solid lines three exponential fits.

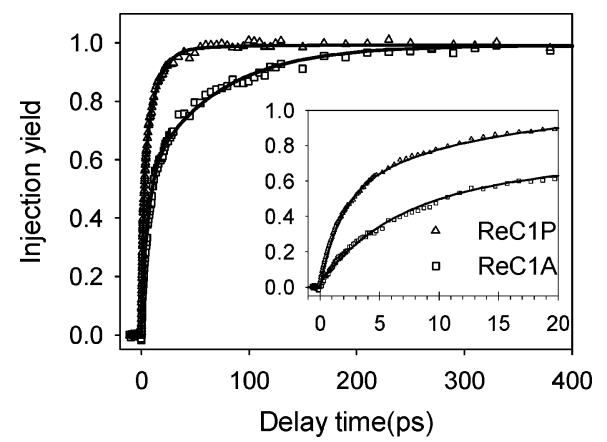

Figure 4. Electron injection kinetics of ReC1P and ReC1A-sensitized $\mathrm{SnO}_{2}$ in ambient environment probed at $2130 \mathrm{~cm}^{-1}$ after $400 \mathrm{~nm}$ excitation. The symbols are experimental data and solid lines are fits using two-exponentials rise.

question, the electron injection kinetics for ReC1A on and ReC1P on $\mathrm{SnO}_{2}$ should also be compared. Figure 4 shows electron injection kinetics of $\mathrm{ReC} 1 \mathrm{P}$ - and $\mathrm{ReC} 1 \mathrm{~A}$-sensitized $\mathrm{SnO}_{2}$ films in ambient environment probed at $2130 \mathrm{~cm}^{-1}$ after $400 \mathrm{~nm}$ excitation. The signal at this wavelength contains only the absorption of the injected electrons in $\mathrm{SnO}_{2}$. It was shown previously that the growth kinetics of electron absorption signal and oxidized peak also agreed with each other for both $\mathrm{ReC} 1 \mathrm{~A} /$ $\mathrm{SnO}_{2}{ }^{42}$ and $\mathrm{ReC} 1 \mathrm{P} / \mathrm{SnO}_{2}{ }^{46}$ However, it was difficult to measure accurate transient vibrational spectra of the adsorbate in these systems because the absorption cross sections of $\mathrm{CO}$ stretching bands of the adsorbate are much smaller than that of injected electrons in $\mathrm{SnO}_{2}$. For these reasons, no attempt was made to record the adsorbate vibrational spectra and only the electron injection kinetics traces are shown here.

As shown in Figure 4, electron injection in $\mathrm{ReC} 1 \mathrm{P} / \mathrm{SnO}_{2}$ is faster than $\mathrm{ReC} 1 \mathrm{~A} / \mathrm{SnO}_{2}$. For $\mathrm{ReC} 1 \mathrm{~A}$, the injection traces reached maximum at $\sim 400 \mathrm{ps}$ and there is no noticeable change in the 400 ps to $1 \mathrm{~ns}$ window. For ReC1P, the injection kinetics reaches maximum at $\sim 50 \mathrm{ps}$ and there is $\sim 10 \%$ decay of the signal amplitude by $1 \mathrm{~ns}$. It was shown previously that this decay could be attributed to back transfer of the injected electrons in $\mathrm{SnO}_{2}$ with adsorbate cation. ${ }^{46}$ Similar decay was also observed for $\mathrm{ReC} 1 \mathrm{P} / \mathrm{SnO}_{2}$ in $\mathrm{pH}$ buffers. ${ }^{9}$ The growth of the signal can be well fit with two-exponentials rise functions and the fitting parameters are summarized in Table 1 . The fits yield amplitude weighted average time constants of 8 and 41 ps for ReC1P and $\mathrm{ReC} 1 \mathrm{~A}$, respectively. The ratio of these time constants suggests a $\sim 5$ time slower injection in $\mathrm{ReC} 1 \mathrm{~A}$. This is similar to the ratio of the half rise times, which suggests a $\sim 3.6$ time slower injection rate in $\mathrm{ReC} 1 \mathrm{~A}$.

3. RuN3P and RuN3 on $\mathrm{TiO}_{2}$. The UV-visible absorption spectra of RuN3P-sensitized $\mathrm{TiO}_{2}\left(\mathrm{RuN} 3 \mathrm{P} / \mathrm{TiO}_{2}\right)$ and RuN3- 


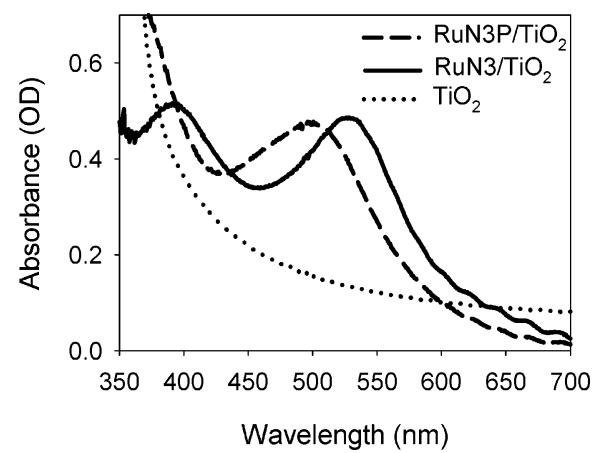

Figure 5. UV-visible absorption spectra of $\mathrm{RuN} 3 \mathrm{P} / \mathrm{TiO}_{2}, \mathrm{RuN} 3 / \mathrm{TiO}_{2}$, and unsensitized $\mathrm{TiO}_{2}$ films in ambient environment. Background due to $\mathrm{TiO}_{2}$ has been subtracted from the spectra of $\mathrm{RuN} 3 \mathrm{P} / \mathrm{TiO}_{2}$ and $\mathrm{RuN} 3 /$ $\mathrm{TiO}_{2}$.

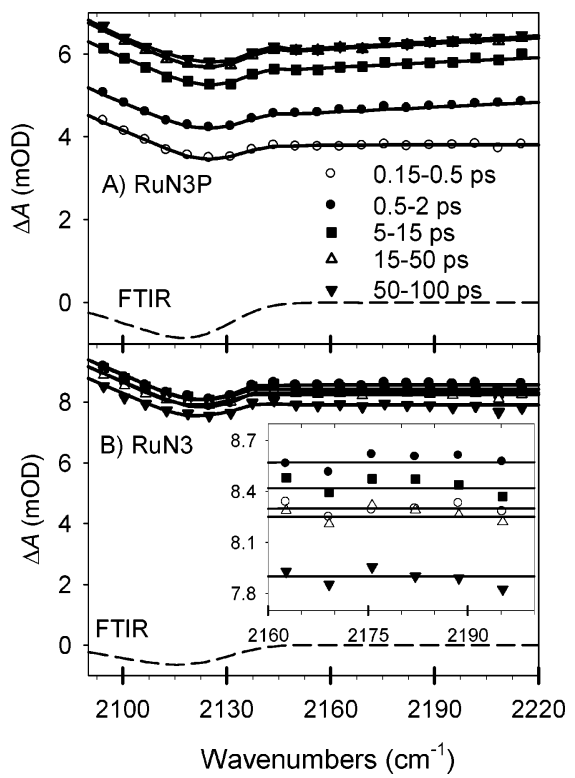

Figure 6. Transient IR absorption spectra of (A) $\mathrm{RuN} 3 \mathrm{P} / \mathrm{TiO}_{2}$ and (B) $\mathrm{RuN} 3 / \mathrm{TiO}_{2}$ at specified delay times after $400 \mathrm{~nm}$ excitation. Also shown are the FTIR spectra (dashed lines) of RuN3P and RuN3, whose peaks have been plotted in the negative direction for better comparison with the transient spectra. The inset in panel $\mathrm{B}$ shows the expanded spectra of $\mathrm{RuN} 3 / \mathrm{TiO}_{2}$ in the $2160-2220 \mathrm{~cm}^{-1}$ region.

sensitized $\mathrm{TiO}_{2}\left(\mathrm{RuN} 3 / \mathrm{TiO}_{2}\right)$ are compared in Figure 5. Also shown is the spectrum of unsensitized $\mathrm{TiO}_{2}$ films, which has been subtracted from the spectra of $\mathrm{RuN} 3 \mathrm{P} / \mathrm{TiO}_{2}$ and $\mathrm{RuN} 3 /$ $\mathrm{TiO}_{2}$. RuN3 shows two ${ }^{1}$ MLCT peaks at $\sim 390$ and $525 \mathrm{~nm} .{ }^{8,10}$ The peaks of RuN3P are blue-shifted to $\sim 350$ and $500 \mathrm{~nm}$. The peak at $\sim 370 \mathrm{~nm}$ is not well resolved due to the onset of strong absorption of $\mathrm{TiO}_{2}$ at $<380 \mathrm{~nm}$. Unlike in ReC1A and ReC1P, the energies of the MLCT band in RuN3P and RuN3 (from the Ru d orbital to $\pi^{*}$ orbitals of bipyridine) are dependent on the nature of the anchoring group, suggesting a strong perturbation of the anchoring group on the energy of $\pi^{*}$ orbitals of bipyridine.

The transient IR absorption spectra of $\mathrm{RuN} 3 \mathrm{P} / \mathrm{TiO}_{2}$ and $\mathrm{RuN} 3 / \mathrm{TiO}_{2}$ measured after $400 \mathrm{~nm}$ excitation are shown in Figure 6 A,B. Also shown are the FTIR spectra of these complexes on $\mathrm{TiO}_{2}$, whose peaks have been plotted along the negative direction to facilitate comparison with the transient spectra. In this spectra region, the only noticeable vibrational features of the adsorbate are the $\mathrm{CN}$ stretching bands of the NCS groups, which center at $2117 \mathrm{~cm}^{-1}$ for both RuN3 and RuN3P. It was shown previously that the $\mathrm{CN}$ stretching bands of RuN3 shift to $\sim 2040$ and $2075 \mathrm{~cm}^{-1}$ in the excited-state

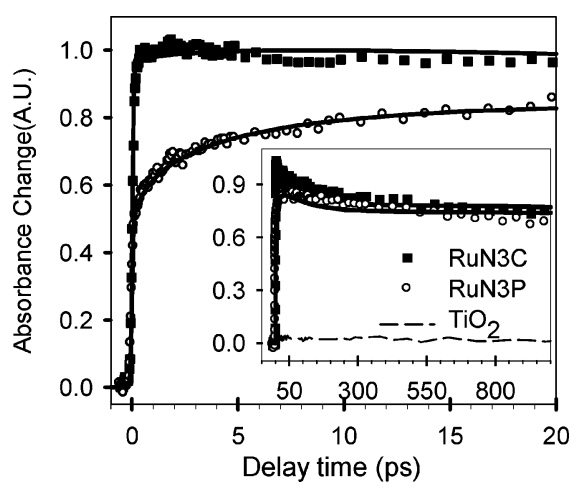

Figure 7. Comparison of the growth and decay kinetics of electron absorption signal (at $2180 \mathrm{~cm}^{-1}$ ) in $\mathrm{RuN} 3 / \mathrm{TiO}_{2}$ and $\mathrm{RuN} 3 \mathrm{P} / \mathrm{TiO}_{2}$ measured after $400 \mathrm{~nm}$ excitation. The inset shows the kinetics on the longer time scale.

and $\sim 2020$ and $2065 \mathrm{~cm}^{-1}$ in the oxidized form. ${ }^{47}$ The transient IR spectra in this region consist of the broad absorption of injected electrons and the vibrational features of the adsorbate. The bleach of the ground state $\mathrm{CN}$ stretching modes $\sim 2120$ $\mathrm{cm}^{-1}$ is noticeable in the transient spectra, but absorption bands of the excited and oxidized forms are outside the spectra window. ${ }^{47}$ Furthermore, the amplitudes of the $\mathrm{CN}$ stretching bands are much smaller than the broad absorption of injected electrons. A detailed analysis of its evolution is difficult and is not attempted here. Only the electron absorption signal in the region of $>2160 \mathrm{~cm}^{-1}$ will be analyzed to compare the injection kinetics. In RuN3/TiO 2 , The amplitude of the electron signals at the earliest delay time window $(0.15-0.5 \mathrm{ps})$ nearly reaches maximum. In $\mathrm{RuN} 3 \mathrm{P} / \mathrm{TiO}_{2}$, the amplitude at $0.15-0.5 \mathrm{ps}$ is about $60 \%$ of the maximum, and the signal reaches maximum value at around $50 \mathrm{ps}$.

The growth of the electron absorption signal can be monitored to follow the electron injection kinetics. Such kinetic traces, probed at $2180 \mathrm{~cm}^{-1}$, for $\mathrm{RuN} 3 / \mathrm{TiO}_{2}$ and $\mathrm{RuN} 3 \mathrm{P} / \mathrm{TiO}{ }_{2}$ are compared in Figure 7. These traces have been normalized to correspond to the same number of absorbed photons by the sensitizer molecules. This quantity was calculated from the total absorbed photons (from OD of adsorbate + film at $400 \mathrm{~nm}$ ) and the percentage of absorption by adsorbate molecules (OD of adsorbate/total OD). Both injection kinetics are biphasic, consisting of a $<100$ fs ultrafast component and slower component on the ps and longer time scale. In addition, both traces also show similar decay on the 50 to 1000 ps time scale. The biphasic electron injection from $\mathrm{RuN} 3$ to $\mathrm{TiO}_{2}$ is well understood: the ultrafast ( $<100 \mathrm{fs}$ ) component is attributed to injection from unrelaxed singlet states, and the slow components to injection from relaxed 3MLCT state near the band edge. ${ }^{19-33}$ The rise time of the fast component depends on both injection rate from the unrelaxed state and the intramolecular relaxation within the excited-state manifold. Since these components originate from different states and have different physical meaning, it is not informative to define an average time in comparing these biphasic injection dynamics. Instead, we should compare the ultrafast and slower components separately.

It was shown previously that the simplest kinetic model that can account for the effect of competition between electron injection and intramolecular relaxation, and allow the comparison of the biphasic injection kinetics is a two-state injection model. ${ }^{24,31,32,35,39,48}$ In this model, shown in Figure 8, photoexcitation of the adsorbate prepares an unrelaxed excited state $\left(\mathrm{S}^{* *}\right.$ or $\left.{ }^{1} \mathrm{MLCT}^{*}\right)$. Electron injection from this state occurs with rate constant $k_{1}$, which competes with intramolecular relaxation within the excited-state manifold (with rate constant $k_{2}$ ). Electron 


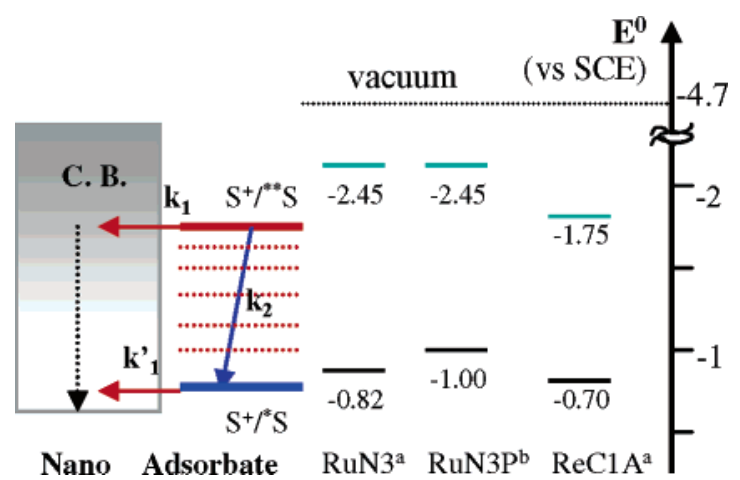

Figure 8. Schematic diagram of the two-state electron injection model and redox potential of ${ }^{1}$ MLCT state prepared by $400 \mathrm{~nm}$ excitation and relaxed ${ }^{3}$ MLCT state. Footnote a: data taken from ref 24 . Footnote b: data taken from refs 8 and 21 (see text).

injection from the relaxed state ( $\mathrm{S}^{*}$ or $\left.{ }^{3} \mathrm{MLCT}\right)$ occurs with rate constant $k_{1}^{\prime}$. For both Ru and Re complexes, the relaxed excitedstate is near the semiconductor conduction band edge, $k_{1}^{\prime}$ is expected to be significantly slower than $k_{1}$ due to the much lower density of conduction band states near the band edge. Assuming $k_{1}^{\prime} \ll k_{1}+k_{2}$, the injection kinetics can be expressed $\operatorname{as}^{24}$

$$
\begin{aligned}
N_{\mathrm{e}}(t)=N_{0}\left[\frac{k_{1}}{k_{1}+k_{2}}\left(1-\mathrm{e}^{-\left(k_{1}+k_{2}\right) t}\right)+\right. & \\
& \left.\frac{k_{2}}{k_{1}+k_{2}}\left(1-\mathrm{e}^{-k_{1}^{\prime} t}\right)\right]
\end{aligned}
$$

where $N_{\mathrm{e}}(t)$ is the time-dependent population of injected electrons and $\mathrm{N}_{0}$ the population of initially excited molecules. Equation 2 predicts biphasic injection kinetics, consisting of a fast component with rate constant $k_{1}+k_{2}$ and a slower component with rate constant $k_{1}^{\prime}$. Since $1 / k_{2}$ is often $<100 \mathrm{fs}$ for these molecules, ${ }^{31,32}$ this measurement does not have sufficient time resolution to directly extract $k_{1}$ from the observed rate of the fast component. An alternative approach is to compare the amplitude of the fast injection component, which is determined by the ratio of the rate constants $k_{1} / k_{2}$ and is a very sensitive indication of changes in $k_{1}$. To accommodate the inhomogeneity of the interfacial process, the above equation can be extended to include multiexponential slow components. This model can also be used to describe the injection kinetics in $\mathrm{ReC} 1 \mathrm{P}$ and $\mathrm{ReC} 1 \mathrm{~A}$, for which $k_{1} \ll k_{2}$ (due to the presence of the $\mathrm{CH}_{2}$ group), and injection kinetics is dominated by the slow component as shown in Figure 3.

With an IR probe the signal amplitude depends on both the population and the absorption cross section of the injected electrons. ${ }^{24,37}$ The ultrafast injection component produces hot electrons high above the $\mathrm{TiO}_{2}$ band edge, which undergo significant energy relaxation on the ns time scale and IR absorption cross section decay. ${ }^{24}$ Negligible cross section decays were observed for the electrons injected in the slow injection components, which were produced near the band edge. To obtain the population kinetics of the injected electrons, the cross section decay of hot electrons need to be de-convolved from the observed IR signal, as was demonstrated in a previous study of $\mathrm{RuN} 3 / \mathrm{TiO}_{2}:{ }^{24}$

$$
\begin{aligned}
S_{\mathrm{e}}(t)=N_{0}\left[\frac{k_{1}}{k_{1}+k_{2}}\left(1-\mathrm{e}^{-\left(k_{1}+k_{2}\right) t}\right) \sigma_{\mathrm{h}}(t)+\right. & \\
& \left.\frac{k_{2}}{k_{1}+k_{2}}\left(1-\mathrm{e}^{-k_{1}^{\prime} t}\right) \sigma_{c}\right]
\end{aligned}
$$

where $\sigma_{\mathrm{h}}(t)$ and $\sigma_{\mathrm{c}}$ indicates the cross section for the hot and relaxed electrons.

The injection kinetics in $\mathrm{RuN} 3 / \mathrm{TiO}_{2}$ and $\mathrm{RuN} 3 \mathrm{P} / \mathrm{TiO}_{2}$ are fit using eq 3 . The value of $1 / \mathrm{k}_{2}$ in RuN3 was measured to be $\sim 75 \mathrm{fs}$, and it is assumed to be the same for RuN3P. ${ }^{31,32}$ The hot electron cross section decay was shown to be well characterized by a biexponential function with time constants and amplitudes (in parenthesis) of $90 \mathrm{ps}(40 \%)$ and $\gg 1 \mathrm{~ns}$ $(60 \%)\left(\right.$ or $\left.\sigma_{\mathrm{h}}(t) / \sigma_{\mathrm{c}}=0.67 \mathrm{e}^{-t / 90 \mathrm{ps}}+1\right)$ for $\mathrm{RuN} 3 / \mathrm{TiO}_{2}{ }^{24} \mathrm{The}$ slow components were fit by a stretching exponential function for comparison with previous study. ${ }^{24}$ The fitting results are summarized in Table 2. The amplitude of the fast component is larger in $\mathrm{RuN} 3 / \mathrm{TiO}_{2}$ than $\mathrm{RuN} 3 \mathrm{P} / \mathrm{TiO}_{2}$, indicating a faster injection rate from unthermalized excited-state in the former. From the relative amplitude, the two-state injection model, i.e., eq 3, suggests a relative rate of $\sim 4$ times faster in $\mathrm{RuN} 3 / \mathrm{TiO}_{2}$. The rate of slow injection component in $\mathrm{RuN} 3 \mathrm{P} / \mathrm{TiO}_{2}$ is about 9 times faster than $\mathrm{RuN} 3 / \mathrm{TiO}_{2}$.

4. RuN3P and RuN3 on $\mathrm{SnO}_{2}$. To further test the dependence of anchoring group effect on the nature of semiconductor, the injection kinetics for $\mathrm{RuN} 3 \mathrm{P}$ and $\mathrm{RuN} 3$ on $\mathrm{SnO}_{2}$ are also compared. The UV-visible absorption spectra of RuN3Psensitized $\mathrm{SnO}_{2}\left(\mathrm{RuN} 3 \mathrm{P} / \mathrm{SnO}_{2}\right), \mathrm{RuN} 3$-sensitized $\mathrm{SnO}_{2}(\mathrm{RuN} 3 /$ $\mathrm{SnO}_{2}$ ) are compared in Figure 9. Background absorption or scattering due to naked $\mathrm{SnO}_{2}$ is subtracted from the spectra of $\mathrm{N} 3 \mathrm{P} / \mathrm{SnO}_{2}$ and $\mathrm{N} 3 / \mathrm{SnO}_{2}$. RuN3 shows two ${ }^{1} \mathrm{MLCT}$ peaks at 390 and $525 \mathrm{~nm}$, similar to those on $\mathrm{TiO}_{2} \cdot{ }^{8}, 10$ The peaks of RuN3P are blue-shifted to 350 and $500 \mathrm{~nm}$, also similar to those on $\mathrm{TiO}_{2}$.

The electron injection kinetics from RuN3 and RuN3P to $\mathrm{SnO}_{2}$ are compared in Figure 10. These kinetics traces are obtained by monitoring the absorption of injected electrons in $\mathrm{SnO}_{2}$ at $2180 \mathrm{~cm}^{-1}$ after $400 \mathrm{~nm}$ excitation. Negligible signal was observed in unsensitized films under the same condition. The injection processes are completed at $\sim 500 \mathrm{ps}$ in both RuN3/ $\mathrm{SnO}_{2}$ and $\mathrm{RuN} 3 \mathrm{P} / \mathrm{SnO}_{2}$. The kinetics are similar in these films except at early delay times, as shown in the inset of Figure 9. Both contains very small amplitude of $<100$ fs component ( $\sim 7 \%$ in RuN3 and $4 \%$ in RuN3P). The majority of injection occurs from the relaxed state ${ }^{3} \mathrm{MLCT}$ of these complexes. The injection kinetics can be fit by multiexponential rise functions. The best fit of these traces requires three exponentials in addition to the $<100 \mathrm{fs}$ component. The amplitude and time constant of these exponentials rise functions, their average time constants and half rise times are listed in Table 3. Both average time constants and half rise-times indicate that the rates of the electron injection processes in $\mathrm{RuN} 3 \mathrm{P} / \mathrm{SnO}_{2}$ and $\mathrm{RuN} 3 / \mathrm{SnO}_{2}$ are similar.

5. Electronic Structures of the Model Complexes. The Cartesian coordinates of the optimized structures for the four model complexes, $\operatorname{Re}(\mathbf{R} 1 X$-bpy $)(\mathrm{CO})_{3}(\mathrm{Cl})$ and $\operatorname{Re}(\mathbf{R} \mathbf{X}$-bpy $)$ $(\mathrm{CO})_{3}(\mathrm{Cl})\left(\mathrm{X}=\mathrm{PO}_{3}{ }^{2-}\right.$ and $\left.\mathrm{COO}^{-}\right)$, are listed in the Supporting Information. Optimization yielded molecular geometries where phosphonate group only attached with two oxygen atoms and the carboxylate group only with one oxygen atom to the metal center. Any attempt to locate minima with three and two oxygen atoms attached to $\mathrm{Ti}$, respectively, to recover 6-fold coordination by stepwise frozen and then fully relaxed geometry optimizations in all cases yielded the under-coordinated structures, so 
TABLE 2: Parameters of Fit to the Electron Injection Kinetics of $\mathrm{RuN} 3 / \mathrm{TiO}_{2}$ and $\mathrm{RuN3P} / \mathrm{TiO}_{2}$ by $\mathrm{Eq} 3$

\begin{tabular}{lcccccccc}
\hline & \multicolumn{2}{c}{ fast component $^{a}$} & & \multicolumn{2}{c}{ slow component $^{b}$} & & \\
\cline { 2 - 3 } sensitizers & $A$ & $\tau_{1}$ & & $B$ & $\tau(\alpha)$ & $k_{1} / k_{2}$ & $\phi_{\text {inj }}^{\text {hot }}$ \\
\hline RuN3 & $71 \%$ & $<100 \mathrm{fs}$ & & $29 \%$ & $42 \mathrm{ps}(0.5)$ & 1.47 & 0.59 \\
RuN3P & $37 \%$ & $<100 \mathrm{fs}$ & & $63 \%$ & $4.6 \mathrm{ps}(0.5)$ & 0.35 & 0.26
\end{tabular}

${ }^{a}$ The fast component is fit by $a<100$ fs exponential rise with amplitude $A .{ }^{b}$ The slow components are model by stretched exponential functions with amplitude $B$, characteristic lifetime $\left(\tau^{\prime}\right)$ and distribution parameters $(\alpha)$ in parenthesis. $k_{1} / \mathrm{k}_{2}$ is calculated from $A / B=k_{1} / k_{2}\left(\sigma_{\mathrm{h}}(0) /\right.$ $\left.\sigma_{\mathrm{c}}\right)$ and $\phi_{\text {inj }}^{\text {hot }}$ is defined as $k_{1} /\left(k_{1}+k_{2}\right){ }^{24}$

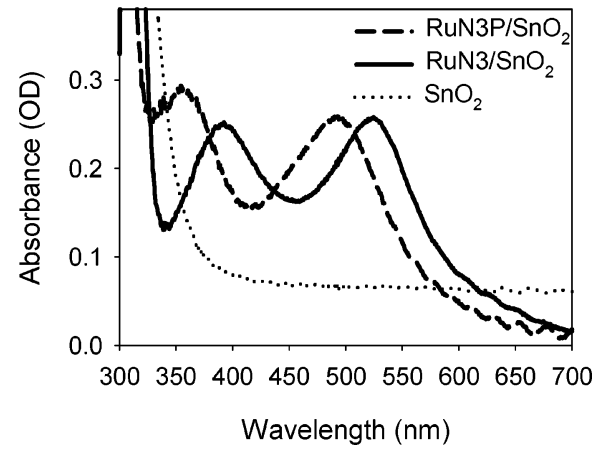

Figure 9. UV-visible absorption spectra of $\mathrm{RuN} 3 \mathrm{P} / \mathrm{SnO}_{2}, \mathrm{RuN} 3 / \mathrm{SnO}_{2}$, and unsensitized $\mathrm{SnO}_{2}$ films. Background absorption/scattering due to $\mathrm{SnO}_{2}$ has been subtracted from the spectra of $\mathrm{RuN} 3 \mathrm{P} / \mathrm{TiO}_{2}$ and $\mathrm{RuN} 3 /$ $\mathrm{TiO}_{2}$.

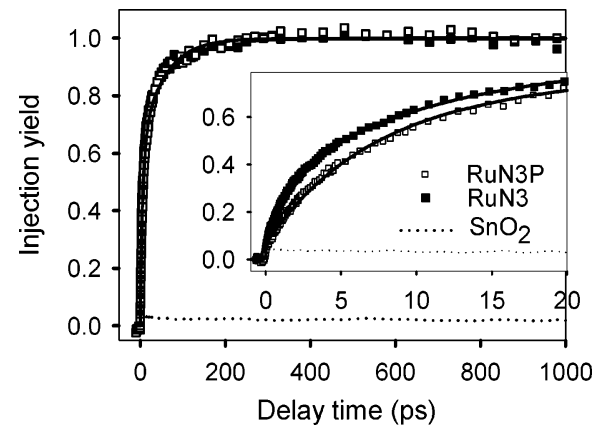

Figure 10. Electron injection kinetics of N3P-sensitized $\mathrm{SnO}_{2}$ and N3sensitized $\mathrm{SnO}_{2}$ and the background signal of naked $\mathrm{SnO}_{2}$ films in ambient environment probed at $2180 \mathrm{~cm}^{-1}$ after $400 \mathrm{~nm}$ excitation.

TABLE 3: Parameters for Multiexponential Fits to and Half-Rise Times of the Electron Injection Kinetics of $\mathrm{N} 3 / \mathrm{SnO}_{2}$ and $\mathrm{N} 3 \mathrm{P} / \mathrm{SnO}_{2}$ in Ambient Environment ${ }^{a}$

\begin{tabular}{lll}
\hline & $\mathrm{N} 3 / \mathrm{SnO}_{2}$ & $\mathrm{~N} 3 \mathrm{P} / \mathrm{SnO}_{2}$ \\
\hline$A_{\text {fr }}(<100 \mathrm{fs})$ & 7 & 4 \\
$\tau_{1} / \mathrm{ps}\left(A_{1}\right)$ & $1.4(22)$ & $2.7(25)$ \\
$\tau_{2} / \mathrm{ps}\left(A_{2}\right)$ & $8.8(46)$ & $15(54)$ \\
$\tau_{3} / \mathrm{ps}\left(A_{3}\right)$ & $80(25)$ & $108(17)$ \\
$\tau_{\text {ave }}, \mathrm{ps}$ & 26 & 28 \\
$\tau_{1 / 2}, \mathrm{ps}$ & 6.3 & 8.0
\end{tabular}

${ }^{a} \tau_{n}$ and $A_{n}$ (in percentage) are the lifetimes and amplitudes, respectively, of the $n$th exponential in the three-exponential fits. $\tau_{\text {ave }}$ is amplitude-weighted-average-time-constant as defined in eq 1. $\tau_{1 / 2}$ is defined as the time of $50 \%$ injection yield.

that we concluded the six-coordinate structures do not exist with the present choice of $\mathrm{Ti}$ ligands.

Figure 11 displays the HOMO, LUMO, and LUMO+1 isosurfaces and orbital energies of $\operatorname{Re}(\mathbf{R} 1 \mathbf{X}-$ bpy $) \mathrm{L}^{\prime}(X=\mathbf{P}$ and A) complexes in their singlet electronic ground states. Also listed are the excitation energies in $\mathrm{eV}$, oscillator strengths of the lowest excited singlet $\pi^{*} S_{1}$ state, which corresponds roughly to $\mathrm{HOMO} \rightarrow \mathrm{c}_{1}(\mathrm{LUMO})+\mathrm{c}_{2}(\mathrm{LUMO}+1)$, with $\mathrm{S}_{1} \mathrm{CI}$ coefficients $c_{1}$ and $c_{2}$. The HOMO is in all three cases localized on the Re and Re ligand system and does not mix with bpy MOs. The LUMO and LUMO+1 MOs correspond to bpy $\pi^{*}$ and TiL MOs and do not mix much with the Re system. Therefore, it is reasonable to state that the $\mathrm{S}_{1}$ state with electronic excitation from the HOMO to the LUMO and/or LUMO+1 corresponds to a charge transfer from Re to the TiL-bpy system. The TDDFT excitation energies of these models are nearly identical with $\Delta E=2.03$ and $2.08 \mathrm{eV}$ for compounds with $\mathbf{X}=$ $\mathbf{P}$ and $\mathbf{A}$, respectively. Three major differences are noticeable when comparing the complexes with phosphonate and carboxylate anchoring group. First, in $\operatorname{Re}(\mathbf{R} 1 P-b p y) L^{\prime}$, the LUMO+1 and LUMO MOs are switched, with the TiL MO lower in energy than the bpy $\pi^{*}$ MO. Furthermore, both LUMO and LUMO +1 are nearly degenerate in $\operatorname{Re}(\mathbf{R} 1 \mathbf{P}-$ bpy $) \mathrm{L}^{\prime}$, separated by only $0.19 \mathrm{eV}$ from each other, while in the $\operatorname{Re}(\mathbf{R} 1 \mathrm{~A}-\mathrm{bpy}) \mathrm{L}^{\prime}$ the separation is $0.71 \mathrm{eV}$, with reversed orbital order. Second, the CI coefficient of the TiL MO is larger with 0.194 in the case of $\operatorname{Re}(\mathbf{R} 1 \mathbf{P}-$ bpy $) \mathrm{L}^{\prime}$ when compared to $\operatorname{Re}(\mathbf{R} \mathbf{1 A}-\mathrm{bpy}) \mathrm{L}^{\prime}$ where it is less than 0.1 . Third, the $\pi^{*} \mathrm{MO}$ of the $\operatorname{Re}(\mathbf{R} 1 \mathbf{P}-$ bpy) $\mathrm{L}^{\prime} \mathrm{LUMO}+1$ orbital possess noticeable density on the Ti center, which is not the case for LUMO of the $\operatorname{Re}(\mathbf{R 1 A}-b p y) \mathrm{L}^{\prime}$ compound. All three peculiarities point to the same direction, namely a stronger charge-transfer component from the bpy $\pi$-system to the $\mathrm{TiO}_{2}$ metal center with the phosphonate anchoring group. In line with this finding is the fact that the HOMO energies of the Re-free anionic complexes are in the order R1P-bpy $(+0.645 \mathrm{eV})<$ R1A-bpy $(+0.909 \mathrm{eV})$. Furthermore, even without the bpy- $\operatorname{Re}(\mathrm{CO})_{3}(\mathrm{Cl})$ unit, the LUMO of R1P-H is lower than the LUMOs of R1A-H. These results suggest that the stronger mixing of bpy $\pi^{*}$ with TiL MO in $\operatorname{Re}(\mathbf{R} 1 \mathbf{P}-b p y) L^{\prime}$ is a property of the phosphonate anchoring group and is attributed to the lower LUMO orbital in this group.

The results for $-\mathrm{CH}_{2}$-free $\operatorname{Re}(\mathbf{R} \mathbf{0 X}-\mathrm{bpy}) \mathrm{L}^{\prime}(\mathrm{X}=\mathrm{P}$ and $\mathrm{A})$ compounds are shown in Figure 12. The excitation energies $\Delta E$ of $-\mathrm{CH}_{2}$-free $\mathrm{Re}\left(\mathbf{R} \mathbf{0 X}\right.$-bpy) $\mathrm{L}^{\prime}$ compounds are lower compared to the $-\mathrm{CH}_{2}$-containing $\operatorname{Re}(\mathbf{R} 1 \mathbf{X}$-bpy $) \mathrm{L}^{\prime}$ compounds by 0.09 and $0.17 \mathrm{eV}$ for $\mathbf{X}=\mathbf{P}$ and $\mathbf{A}$, respectively. Again, the HOMO MOs are strongly localized on the Re center and the Re ligand system. LUMO and LUMO+1 MOs are significantly lowered by about 0.2 and $0.4 \mathrm{eV}$ in $\operatorname{Re}\left(\mathbf{R} \mathbf{X X}\right.$-bpy) $\mathrm{L}^{\prime}$ with $\mathrm{X}=\mathbf{P}$ and $\mathbf{A}$, respectively. In both $-\mathrm{CH}_{2}$-free $\mathrm{Re}\left(\mathbf{R} \mathbf{0 X}\right.$-bpy) $\mathrm{L}^{\prime}$ compounds, the qualitative appearance and order of the LUMO and $\mathrm{LUMO}+1$ is identical, and the orbital with the highest localization on Ti among them is the LUMO+1. In all cases, this MO has less than $0.1 \mathrm{CI}$ coefficient in the $\mathrm{S}_{1}$ excited-state wavefunction. On the other hand, charge localization in the LUMO is much less pronounced than in the rather clear-cut situation of spacer-containing $\operatorname{Re}(\mathbf{R} \mathbf{1 X}$-bpy $) \mathrm{L}^{\prime}$ compounds. Here it is found that the bpy $\pi^{*}$ MO mixes stronger with the Ti center MOs through the carboxylate anchoring group than phosphonate. And, for $\mathrm{X}=\mathbf{A}$, the $\mathrm{LUMO}+1$ has a strong bpy $\pi^{*} \mathrm{MO}$ component mixed in, which is not the case for $\mathrm{X}=\mathbf{P}$. Furthermore, in both $-\mathrm{CH}_{2}$-free model compounds, the electronic interaction between the bpy $\pi^{*} \mathrm{MO}$ and Ti center is stronger than the corresponding $-\mathrm{CH}_{2}$-containing compounds. The HOMO energies of the Re-free anionic complexes are in the order R0P-bpy $(+0.541 \mathrm{eV})<$ R0A-bpy $(+0.733 \mathrm{eV})$, confirming the stabilization of the excess electron relative to the $-\mathrm{CH}_{2}$-containing compounds in the case of anchoring group $\mathbf{P}$ and even more so in $\mathbf{A}$.

\section{Discussion}

Transient absorption studies reveals that the effect of the anchoring group on the interfacial electron injection rate appears 


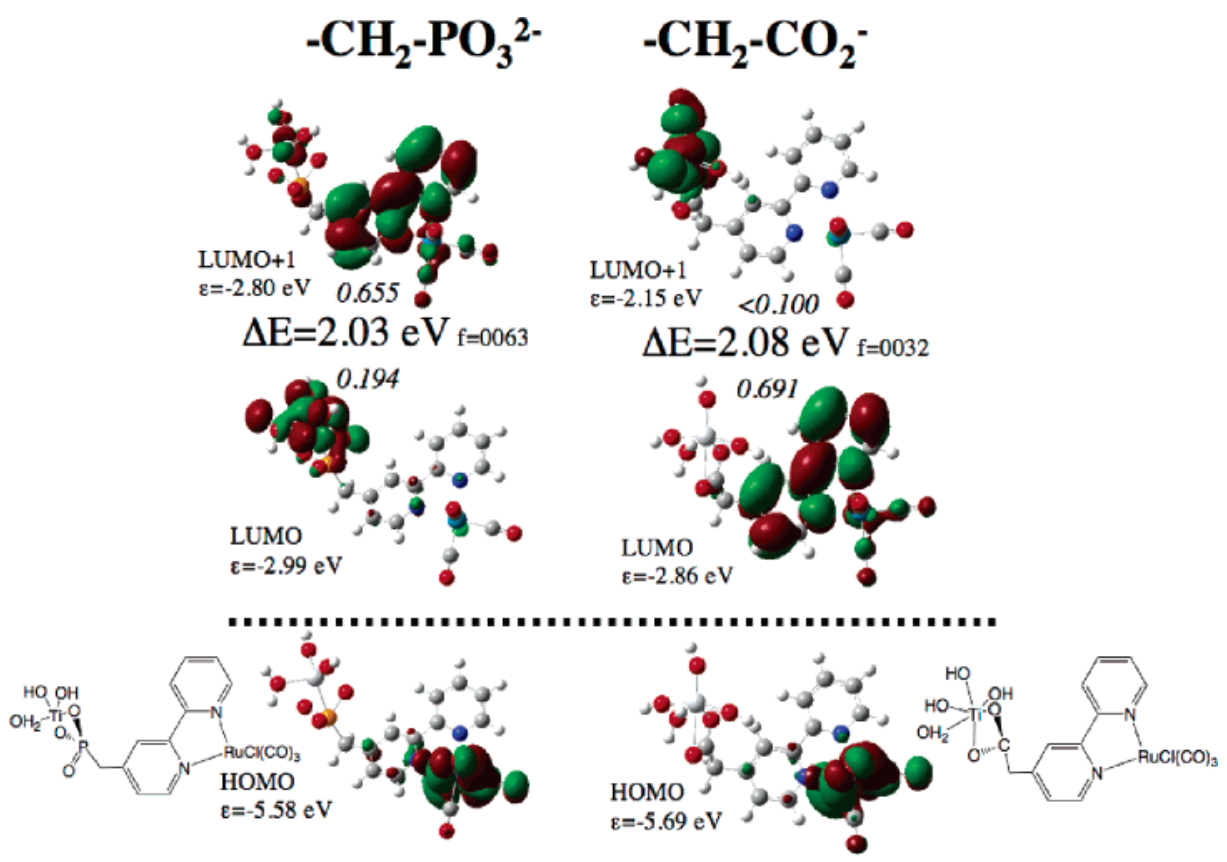

Figure 11. B3LYP/Lanl2DZ geometries, orbital energies (in eV), and isovalue surfaces $\left(0.002 \mathrm{e}^{1 / 2} / \AA^{3}\right)$ of HOMO, LUMO, and LUMO+1, and CI coefficients (in italic) and oscillator strengths $f$ for the first excited singlet state for spacer-containing $\operatorname{Re}(\mathrm{R} 1 \mathrm{X}-\mathrm{bpy})(\mathrm{CO})_{3} \mathrm{Cl}\left(\mathrm{R} 1 \mathrm{X}=-\mathrm{CH}{ }_{2}-\mathrm{X}-\right.$ TiL) model systems with $\mathrm{X}=\mathbf{P}$ and $\mathbf{A}$.

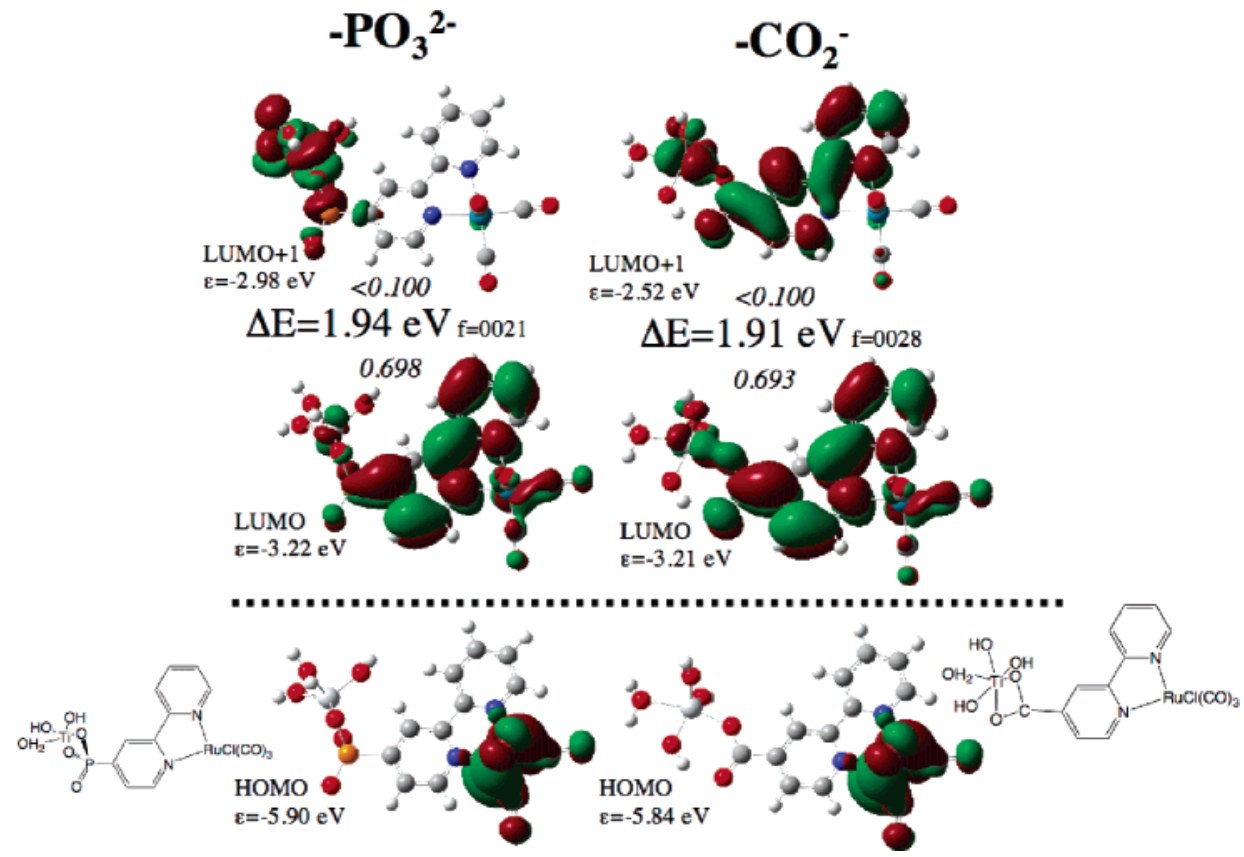

Figure 12. B3LYP/Lanl2DZ geometries, orbital energies (in eV), and isovalue surfaces $\left(0.002 \mathrm{e}^{1 / 2} / \AA^{3}\right)$ of HOMO, LUMO, and LUMO+1, and CI coefficients in italic and oscillator strengths $f$ for the first excited singlet state for spacer-free $\mathrm{Re}(\mathrm{R} 0 \mathrm{X}-\mathrm{bpy})(\mathrm{CO}) 3 \mathrm{Cl}$ model systems with $\mathrm{X}=$ $\mathbf{P}$ and $\mathbf{A}$.

to be different in the $\mathrm{Re}$ and $\mathrm{Ru}$ bipyridyl complexes. For $\mathrm{ReC} 1 \mathrm{P}$ and $\mathrm{ReC} 1 \mathrm{~A}$, in which there is a $\mathrm{CH}_{2}$ group between the anchoring group and the bpy ligand, injection rate is faster with phosphonate group than carboxylate group on both $\mathrm{TiO}_{2}$ and $\mathrm{SnO}_{2}$, as shown in Figures 3 and 4. For RuN3 and RuN3P, in which the anchoring groups are directly connected to the bpy ligand, the effect of the anchor appears to be different on $\mathrm{TiO}_{2}$ and $\mathrm{SnO}_{2}$. On $\mathrm{SnO}_{2}$, the injection rates through both anchoring groups are similar, as shown in Figure 10. On $\mathrm{TiO}_{2}$, shown in Figure 7, the anchoring group affects the fast and the slow components of the biphasic injection kinetics differently. With the carboxylate group, the amplitude of the fast component is larger, suggesting a faster injection rate from unrelaxed excited state, while the rate of the slow component, injection from the relaxed ${ }^{3}$ MLCT state, becomes slower. Computational studies of the electronic structures of model adsorbate $-\mathrm{TiO}_{2}$ complexes suggest that for $-\mathrm{CH}_{2}$-containing model compounds, $\mathrm{Re}(\mathrm{R} 1 \mathrm{X}-\mathrm{bpy}) \mathrm{L}^{\prime}$, the electronic interaction between the bpy $\pi^{*} \mathrm{MO}$ and the Ti center, is larger through the phosphate anchoring group than the carboxylate group. On the other hand, for $-\mathrm{CH}_{2}$-free compounds, $\operatorname{Re}(\mathrm{R} 0 \mathrm{X}-\mathrm{bpy}) \mathrm{L}^{\prime}$, with the carboxylate anchoring group, the bpy $\pi^{*} \mathrm{MO}$ overlaps with and extends into the $-\mathrm{COO}^{-}$ $\pi$-system, leading to much larger stabilization of the bpy $\pi^{*}$ $\mathrm{MO}$ and stronger interaction with Ti center than with phosphonate group. 
In the nonadiabatic limit, the total electron injection rate from molecular excited-state into the nanoparticle can be expressed as the sum of ET rates to all possible accepting states in the semiconductor. ${ }^{49-52}$ For electron injection from an adsorbate excited state (redox potential, $E^{\circ}\left(\mathrm{S}^{+} / \mathrm{S}^{*}\right)$ to a semiconductor $k$ state at energy $\epsilon\left(=E-E_{\mathrm{CB}}\right)$ above band-edge, nano ${ }^{-}(\epsilon)$, the reaction can be written as

$$
\mathrm{S}^{*}+\text { nano } \rightarrow \mathrm{S}^{+}+\text {nano }^{-}(\epsilon)
$$

The driving force for this ET reaction is $\Delta G(\epsilon)=\Delta G_{0}+\epsilon$, where $\Delta G_{0}=-e\left(E_{\mathrm{CB}}^{\circ}-E^{\circ}\left(\mathrm{S}^{+} / \mathrm{S}^{*}\right)\right)$ is the free energy change for electron transfer to the conduction band-edge (with flat band potential of $\left.E_{\mathrm{CB}}^{\circ}\right)$. The total ET rate from adsorbate to semiconductor becomes

$$
\begin{array}{r}
k_{\mathrm{ET}}=\left.\frac{2 \pi}{\hbar} \int_{-\infty}^{\infty} \mathrm{d} \epsilon \rho(\epsilon)\left(1-f\left(\epsilon, \epsilon_{F}\right)\right) \bar{H}(\epsilon)\right|^{2} \frac{1}{\sqrt{4 \pi \lambda k_{\mathrm{B}} T}} \times \\
\exp \left[-\frac{\left(\lambda+\Delta G_{0}+\epsilon\right)^{2}}{4 \lambda k_{\mathrm{B}} T}\right]
\end{array}
$$

where, $\rho(\epsilon)$ is the density of electron accepting states at energy $\epsilon$, which can include both bulk, surface and defect states; $H(\epsilon)$ is the average electronic coupling between the adsorbate excitedstate and all $k$ states in the semiconductor at the same energy $\epsilon$; and $\lambda$ is the total reorganization energy which is the sum of inner-sphere $\left(\lambda_{\mathrm{i}}\right)$ and outer-sphere $\left(\lambda_{\mathrm{o}}\right)$ contributions $\left(\lambda=\lambda_{\mathrm{i}}+\right.$ $\left.\lambda_{o}\right)$. The Fermi occupancy factor, $f\left(\epsilon, \epsilon_{\mathrm{F}}\right)$, ensures that electron injection occurs only to unfilled states in the semiconductor. For undoped wide band gap semiconductors that are not under external bias, electron population in the conduction band is negligible and therefore $f\left(\epsilon, \epsilon_{\mathrm{F}}\right)$ is assumed to be 0 .

Within this model, the injection rate depends on the coupling strength between adsorbate and the semiconductor, the reorganization energy, and the density of accepting states. The effects of anchoring groups on interfacial electron transfer should be understood by considering their effects on these quantities. It is reasonable to assume that the reorganization energy is independent of the anchoring group. The density of accepting state depends on the nature of the semiconductor, $\rho(\epsilon)$, and the relative position of adsorbate potential to conduction band edge. It is assumed that the conduction band edge is not affected by the anchoring group (and that it is fixed by the adsorbed water on the surface of the film under ambient condition). When comparing injection kinetics to the same semiconductor, for which $\rho(\epsilon)$ remains unchanged, the anchoring group affects density of accepting states when it changes the energetics of the adsorbate excited state. So the anchoring groups can affect interfacial ET rate by enhancing the electronic coupling and lowering the energy of the excited state. The effect on energetics can be determined directly through experimental data (redox potential of the ground state and $0-0$ transition energy of excited state). The effect on electronic coupling strength is obtained from the computed electronic structure of the model complexes discussed earlier.

ReC1P and ReC1A. The electronic interaction between the bipyridine and anchoring groups is significantly reduced by the $\mathrm{CH}_{2}$ group between them. As a result, the nature of anchoring group has negligible effect on the energy of the HOMO orbital on Re center and the LUMO orbital on bpy $\pi^{*}$. This is evident in the UV-visible absorption spectra of $\mathrm{ReC} 1 \mathrm{~A}$ and $\mathrm{ReC1P}$, which show identical MLCT band positions that are independent of $\mathrm{pH}$ environment. ${ }^{9}$ Comparison of the electronic structures of the model $\operatorname{Re}(\mathrm{R} 1 \mathrm{X}-\mathrm{bpy}) \mathrm{L}^{\prime}(\mathrm{X}=\mathrm{P}$ and $\mathrm{A})$ complexes show that the phosphonate anchoring group enhances the interaction between the bpy $\pi^{*}$ orbital and the Ti center, leading to a stronger electronic coupling matrix element for ET. The stronger coupling strength is attributed to the lower LUMO orbital of the phosphonate group than the carboxylate group. Since the effect is an inherent property of the anchoring groups, similar trend of electronic coupling strength can be expected on $\mathrm{SnO}_{2}$. Although the model complex contains only one anchoring group and one Ti center, similar effects of the anchoring groups on the orbital interaction between bpy and $\mathrm{Ti}$ center can be expected in $\mathrm{ReC} 1 \mathrm{~A}$ and $\mathrm{ReC} 1 \mathrm{P}$ sensitized $\mathrm{TiO}_{2}$ and $\mathrm{SnO}_{2}$. The faster electron injection rate from $\mathrm{ReC} 1 \mathrm{P}$ to $\mathrm{TiO}_{2}$ and $\mathrm{SnO}_{2}$ than from $\mathrm{ReC} 1 \mathrm{~A}$ is attributed to the stronger coupling through the $-\mathrm{CH}_{2}-$ $\mathrm{PO}_{3}{ }^{2-}$ group.

RuN3 and RuN3P. As shown in Figures 5 and 9, replacing $\mathrm{COOH}$ in RuN3 by $\mathrm{PO}_{3} \mathrm{H}_{2}$ (in RuN3P) shifts the lower energy MLCT band to high frequency by $\sim 950 \mathrm{~cm}^{-1}$ (or 120 $\mathrm{meV})$, similar to the change in ${ }^{3} \mathrm{MLCT}$ emission energy reported previously. ${ }^{8}$ The ground state potential $E^{1 / 2}\left(\mathrm{Ru}^{\mathrm{III} / I I}\right)$ was found to be weakly dependent on the anchoring group, changing from $0.68 \mathrm{~V}(\mathrm{SCE})$ in RuN3 to $0.70 \mathrm{~V}(\mathrm{SCE})$ in RuN3P. The potential for the relaxed ${ }^{3}$ MLCT state, calculated from $E^{1 / 2}\left(\mathrm{Ru}^{\mathrm{III} / \mathrm{II}}\right)$ and the energy of the $0-0$ MLCT transition, shifts by $\sim 180 \mathrm{meV}$, from $-1.14 \mathrm{~V}$ (SCE) in RuN3 to $-1.32 \mathrm{~V}$ (SCE) in RuN3P. The value for RuN3 is significantly different from the $-0.82 \mathrm{~V}$ (SCE) reported in other papers, ${ }^{53}$ due to the uncertainty in the estimated $0-0$ transition energy. Adopting the value of $-0.82 \mathrm{~V}$ for RuN3, ${ }^{53}$ and shift of $180 \mathrm{meV},{ }^{8}$ the potential of ${ }^{3} \mathrm{MLCT}$ state in RuN3P, is estimated to be -1.0 $\mathrm{V}(\mathrm{SCE})$. Despite the uncertainty in its absolute position, it is clear that carboxylate group shifts the ${ }^{3}$ MLCT exited state to lower energy, by $\sim 180 \mathrm{meV}$, compared to the phosphonate group. This shift can be attributed to the better orbital overlap of $\pi^{*}$ orbital of bipyridine with the $\mathrm{COO}^{-}$anchoring group, which extends the $\pi^{*}$ orbital into the anchoring group and lowers its energy. This effect is evident in the computed electronic structure of the model complex of $\operatorname{Re}(\mathrm{R} 0 \mathrm{X}-\mathrm{bpy}) \mathrm{L}^{\prime}$. It is also shown that the delocalization of bpy $\pi^{*}$ orbital into carboxylate group leads to a stronger mixing with the Ti center and enhances the electronic coupling strength for ET from the bpy group into $\mathrm{TiO}_{2}$. Although the model complexes involve $\mathrm{Re}$ center and has only one bpy ligand with one anchoring group, the observed effect is a result of the bpy ligand-anchoring group interaction and should be applicable to RuN3 and RuN3P, which contains the ligands with two anchoring groups. Indeed, similar effects have been reported in previous computational studies of anchoring group effect in related $\mathrm{CH}_{2}$-free model compounds. ${ }^{6-8} \mathrm{~A}$ comparison of the LUMO orbitals of RuN3 and RuN3P showed that the carboxylate group stabilized bpy $\pi^{*}$ orbital by extending it into the $\mathrm{COO}^{-}$group. ${ }^{8}$ A comparison of pyridine-4-phosphonic acid and pyridine-4-carboxylic acid on a $\mathrm{TiO}_{2}$ slab showed a lower LUMO orbital energy and stronger mixing with $\mathrm{TiO}_{2}$ with the latter adsorbate. ${ }^{7}$ More recently, a comparison of $\mathrm{Ru}(\text { tpy })_{2}$ (tpy $=2,2^{\prime}: 6^{\prime}, 2^{\prime \prime}$-terpyridine) anchored on a $\mathrm{TiO}_{2}$ cluster indicated that the energy of LUMO orbital (tpy $\left.\pi^{*} \mathrm{MO}\right)$ is lower and its interaction with $\mathrm{TiO}_{2}$ cluster is stronger through the $\mathrm{COOH}$ than the $\mathrm{PO}_{3} \mathrm{H}_{2}$ groups. ${ }^{6}$ These computational and experimental results suggest that when the anchoring groups are directly attached to the bpy ligand (without the $\mathrm{CH}_{2}$ spacer), such as in RuN3 and RuN3P, their effects are 2-fold: the carboxylate group enhances the electronic coupling of bpy with $\mathrm{TiO}_{2}$ and lowers the energy of this orbital (and the ${ }^{3}$ MLCT state). 
For RuN3 and RuN3P on $\mathrm{TiO}_{2}$, the injection kinetics are biphasic, as shown in Figure 7. The fast component results from injection from unrelaxed ${ }^{1}$ MLCT states high above the band edge. The larger fast component amplitude in RuN3 suggests a faster injection rate from the unrelaxed ${ }^{1} \mathrm{MLCT}$ state. The faster injection rate through the carboxylate anchoring group can be attributed to the stronger coupling through this group. However, the rate of the slow component, attributed to injection from the relaxed ${ }^{3} \mathrm{MLCT}$ state, is faster through the phosphonate anchoring group than the carboxylate group despite stronger electronic coupling in the latter. The reversed trend can be attributed to the difference in the ${ }^{3}$ MLCT state energies in these complexes. The $\mathrm{TiO}_{2}$ films in this study are exposed to air and contain significant absorbed water. Assuming a surface proton concentration similar to that at $\mathrm{pH} 7$, the band edge of $\mathrm{TiO}_{2}$ is estimated to be $-0.82 \mathrm{~V},{ }^{54}$ near the relaxed ${ }^{3}$ MLCT states of RuN3 and RuN3P. In this region, the density of electron accepting states changes nearly exponentially with energy, leading to a strong dependence of injection rate with energy of the adsorbate (relative to band edge). This strong dependence was demonstrated in a recent study of the $\mathrm{pH}$ dependence of electron injection from $\mathrm{ReC} 1 \mathrm{P}$ and $\mathrm{ReC} 1 \mathrm{~A}$ into $\mathrm{TiO}_{2} .{ }^{9}$ It was shown that the injection rate changed by 3 orders of magnitude from $\mathrm{pH} 0$ to $\mathrm{pH} 9$ for $\mathrm{ReC} 1 \mathrm{P} / \mathrm{TiO}_{2}$ and the change could be accounted for by considering the variation of density of accepting states resulted from $\mathrm{pH}$ dependent conduction band edge position. Using the same model for density of states in $\mathrm{TiO}_{2}$, it can be estimated that the density of electron accepting state for injection from a state at $-1.0 \mathrm{~V}(\mathrm{RuN} 3 \mathrm{P})$ should be $\sim 10$ larger than a state at $-0.82 \mathrm{~V}(\mathrm{RuN} 3)$. The higher energy of the ${ }^{3}$ MLCT state in RuN3P is responsible for the observed faster rate of its slow injection component, despite its weaker electronic coupling strength than RuN3.

For RuN3 and RuN3P on $\mathrm{SnO}_{2}$, the injection kinetics traces are similar and are dominated by slow injection components. Here, the effect of anchoring group is similar to that of slow injection component of these complexes on $\mathrm{TiO}_{2}$. As discussed earlier, while the $\mathrm{COOH}$ group increases the electronic coupling strength, it lowers the energy of the excited state. These two factors have opposite effects on the injection rate. Using a density of states distribution similar to that was used to account for the $\mathrm{pH}$ dependent injection rate from $\mathrm{ReC} 1 \mathrm{P}$ to $\mathrm{SnO}_{2}$, and assuming a conduction band edge of $\sim-0.32 \mathrm{~V}$, the rate increase due to higher energy in RuN3P can be estimated to be less than a factor of 2. ${ }^{9}$ The weaker dependence of ET rate on the energy of the ${ }^{3} \mathrm{MLCT}$ state can be attributed to the lower band-edge position of $\mathrm{SnO}_{2}\left(0.5 \mathrm{~V}\right.$ lower than $\left.\mathrm{TiO}_{2}\right)$. In this case, electron accepting states are further above the band edge, at which the variation of their density with energy is slower.

\section{Conclusion}

The effects of anchoring groups on electron injection from adsorbate to nanocrystalline thin films were investigated by comparing injection kinetics from ReC1P vs ReC1A and RuN3P vs RuN3. These effects were analyzed by considering how they affect energy of adsorbate excited state and its coupling with the semiconductor. For $\mathrm{ReC} 1 \mathrm{P}$ and $\mathrm{ReC} 1 \mathrm{~A}$, in which there is a $\mathrm{CH}_{2}$ group between the anchoring group and the bpy ligand, injection rate is faster with phosphonate group than carboxylate group on both $\mathrm{TiO}_{2}$ and $\mathrm{SnO}_{2}$. The anchoring groups were shown to have negligible effects on the energetics of relevant orbitals in the Re complexes. Computational studies of the electronic structure of model adsorbate- $\mathrm{TiO}_{2}$ complexes suggest that for $-\mathrm{CH}_{2}$-containing model compounds, $\mathrm{Re}(\mathrm{R} 1 \mathrm{X}-\mathrm{bpy}) \mathrm{L}^{\prime}$, the electronic interaction between the bpy $\pi^{*}$ MO and the Ti center is larger with the phosphonate anchoring group than the carboxylate group, due to the presence of a lower LUMO energy in the former. The observed faster rate through the phosphonate anchoring group can be attributed to a stronger coupling strength for ET from the bpy ligand to $\mathrm{TiO}_{2}$ and $\mathrm{SnO}_{2}$.

For RuN3 and RuN3P on $\mathrm{SnO}_{2}$, the injection kinetics traces are dominated by injection from the relaxed ${ }^{3}$ MLCT state, and the injection rates through both anchoring groups are similar. On $\mathrm{TiO}_{2}$ the anchoring group affects the fast and the slow components of the biphasic injection kinetics differently. With the carboxylate group, the amplitude of the fast component is larger, suggesting a faster injection rate from unrelaxed excited state, while the rate of the slow component (injection from the relaxed ${ }^{3}$ MLCT state) becomes slower. These results and the computational studies of model complexes show that when the anchoring groups are directly connected to the bpy ligand without the $\mathrm{CH}_{2}$ spacer, such as in RuN3 and RuN3P, their effects are 2-fold: the carboxylate group enhances the electronic coupling of bpy with $\mathrm{TiO}_{2}$ and lowers the energy of this orbital (and the ${ }^{3}$ MLCT state). The enhanced electron coupling increases ET rate, while the lower energy level decreases ET rate. The latter effect becomes important when the energy of the injection rates is near or below the conduction band edge, such as the injection from the ${ }^{3}$ MLCT state. These competing factors lead to different effects on $\mathrm{TiO}_{2}$ and $\mathrm{SnO}_{2}$ and on different components of the biphasic injection kinetics.

Acknowledgment. The authors acknowledge the partial financial support by the US DOE, Office of Science (Grant Nos. DE-FG02-98ER14918 and DE-FG02-87ER13808), the Donors of the Petroleum Research Fund, the Emory University Research Committee, and the Alfred P. Sloan Foundation. Computer resources were provided in part by the Oak Ridge National Laboratory's Center for Nanophase Materials Sciences as well as by the Cherry L. Emerson Center of Emory University and the Fukui Institute for Fundamental Chemistry of Kyoto University.

Supporting Information Available: Table S1: The Cartesian coordinates of the optimized structures for the four model complexes, $\operatorname{Re}(\mathbf{R} 1 \mathbf{X}$-bpy $)(\mathrm{CO})_{3}(\mathrm{Cl})$ and $\operatorname{Re}(\mathbf{R} \mathbf{0 X}$-bpy $)(\mathrm{CO})_{3}(\mathrm{Cl})$ $\left(\mathrm{X}=\mathrm{PO}_{3}{ }^{2-}\right.$ and $\left.\mathrm{COO}^{-}\right)$. This material is available free of charge via the Internet at http://pubs.acs.org.

\section{References and Notes}

(1) Nitzan, A.; Ratner, M. A. Science 2003, 300, 1384.

(2) O'Regan, B.; Gratzel, M. Nature 1991, 353, 737.

(3) Yaliraki, S. M.; Kemp, M.; Ratner, M. A. J. Am. Chem. Soc. 1999, $121,3428$.

(4) Di Ventra, M.; Pantelides, S. T.; Lang, N. D. Phys. Rev. Lett. 2000, 84,979

(5) Vondrak, T.; Wang, H.; Winget, P.; Cramer, C. J.; Zhu, X. Y. J. Am. Chem. Soc. 2000, 122, 4700.

(6) Lundqvist, M. J.; Nilsing, M.; Lunell, S.; Aakermark, B.; Persson, P. J. Phys. Chem. B 2006, 110, 20513.

(7) Nilsing, M.; Persson, P.; Ojamaee, L. Chem. Phys. Lett. 2005, 415, 375.

(8) Zabri, H.; Gillaizeau, I.; Bignozzi, C. A.; Caramori, S.; Charlot, M.-F.; Cano-Boquera, J.; Odobel, F. Inorg. Chem. 2003, 42, 6655.

(9) She, C.; Anderson, N. A.; Guo, J.; Liu, F.; Goh, W.; Chen, D.-T.; Mohler, D. L.; Tian, Z.-Q.; Hupp, J.; Lian, T. J. Phys. Chem. B 2005, 109, 19345.

(10) Nazeeruddin, M. K.; Kay, A.; Rodicio, I.; Humphrybaker, R.; Muller, E.; Liska, P.; Vlachopoulos, N.; Gratzel, M. J. Am. Chem. Soc. 1993, 115, 6382.

(11) Pechy, P.; Rotzinger, F. P.; Nazeeruddin, M. K.; Kohle, O.; Zakeeruddin, S. M.; Humphrybaker, R.; Gratzel, M. J. Chem. Soc., Chem. Commun. 1995, 65. 
(12) Zakeeruddin, S. M.; Nazeeruddin, M. K.; Pechy, P.; Rotzinger, F. P.; HumphryBaker, R.; Kalyanasundaram, K.; Gratzel, M.; Shklover, V.; Haibach, T. Inorg. Chem. 1997, 36, 5937.

(13) Gillaizeau-Gauthier, I.; Odobel, F.; Alebbi, M.; Argazzi, R.; Costa,

E.; Bignozzi, C. A.; Qu, P.; Meyer, G. J. Inorg. Chem. 2001, 40, 6073.

(14) Bae, E.; Choi, W.; Park, J.; Shin, H. S.; Kim, S. B.; Lee, J. S. J. Phys. Chem. B 2004, 108, 14093.

(15) Nilsing, M.; Lunell, S.; Persson, P.; Ojamaee, L. Surf. Sci. 2005 $582,49$.

(16) Yan, S. G.; Hupp, J. T. J. Phys. Chem. 1996, $100,6867$.

(17) Haque, S. A.; Tachibana, Y.; Willis, R. L.; Moser, J. E.; Graetzel,

M.; Klug, D. R.; Durrant, J. R. J. Phys. Chem. B 2000, 104, 538.

(18) Heimer, T. A.; Heilweil, E. J.; Bignozzi, C. A.; Meyer, G. J. J. Phys. Chem. A 2000, 104, 4256.

(19) Kuciauskas, D.; Monat, J. E.; Villahermosa, R.; Gray, H. B.; Lewis,

N. S.; McCusker, J. K. J. Phys. Chem. B 2002, 106, 9347.

(20) Tachibana, Y.; Nazeeruddin, M. K.; Gratzel, M.; Klug, D. R.; Durrant, J. R. Chem. Phys. 2002, 285, 127.

(21) Tachibana, Y.; Haque, S. A.; Mercer, I. P.; Moser, J. E.; Klug, D. R.; Durrant, J. R. J. Phys. Chem. B 2001, 105, 7424.

(22) Durrant, J. R.; Tachibana, Y.; Mercer, I.; Moser, J. E.; Gratzel,

M.; Klug, D. R. Z. Phys. Chem. 1999, 212, 93.

(23) Tachibana, Y.; Moser, J. E.; Graetzel, M.; Klug, D. R.; Durrant, J.

R. J. Phys. Chem. 1996, 100, 20056.

(24) Asbury, J. B.; Anderson, N. A.; Hao, E.; Lian, T. J. Phys. Chem. $B$ 2003, 107, 7376 .

(25) Asbury, J. B.; Ellingson, R. J.; Ghosh, H. N.; Ferrere, S.; Nozik, A. J.; Lian, T. J. Phys. Chem. B 1999, 103, 3110

(26) Ellingson, R. J.; Asbury, J. B.; Ferrere, S.; Ghosh, H. N.; Sprague,

J. R.; Lian, T.; Nozik, A. J. J. Phys. Chem. B 1998, 102, 6455.

(27) Hannappel, T.; Burfeindt, B.; Storck, W.; Willig, F. J. Phys. Chem. $B$ 1997, 101, 6799 .

(28) Benko, G.; Kallioinen, J.; Myllyperkio, P.; Trif, F.; KorppiTommola, J. E. I.; Yartsev, A. P.; Sundstrom, V. J. Phys. Chem. B 2004, $108,2862$.

(29) Kallioinen, J.; Benko, G.; Myllyperkio, P.; Khriachtechev, L.; Skarman, B.; Wallenberg, R.; Tuomikoski, M.; Korppi-Tommola, J. E. I.; Sundstrom, V.; Yartsev, A. P. J. Phys. Chem. B 2004, 108, 6365.

(30) Benko, G.; Myllyperkio, P.; Pan, J.; Yartsev, A. P.; Sundstrom, V. J. Am. Chem. Soc 2003, 125, 1118 .

(31) Kallioinen, J.; Benko, G.; Sundstrom, V.; Korppi-Tommola, J. E. I.; Yartsev, A. P. J. Phys. Chem. B 2002, 106, 4396.

(32) Benko, G.; Kallioinen, J.; Korppi-Tommola, J. E. I.; Yartsev, A.

P.; Sundstrom, V. J. Am. Chem. Soc. 2002, 124, 489.

(33) Heimer, T. A.; Heilweil, E. J. J. Phys. Chem. B 1997, 101, 10990.

(34) Anderson, N. A.; Lian, T. Ann. Rev. Phys. Chem. 2005, 56, 491.

(35) Asbury, J. B.; Wang, Y. Q.; Hao, E. C.; Ghosh, H. N.; Lian, T. Res. Chem. Interm. 2001, 27, 393.

(36) Schnadt, J.; Bruehwiler, P. A.; Patthey, L.; O’Shea, J. N.;
Soedergren, S.; Odelius, M.; Ahuja, R.; Karis, O.; Baessler, M.; Persson, P.; Siegbahn, H.; Lunell, S.; Martensson, N. Nature (London) 2002, 418 , 620.

(37) Asbury, J. B.; Hao, E.; Wang, Y.; Lian, T. J. Phys. Chem. B 2000, 104, 11957.

(38) Wang, Y.; Asbury, J. B.; Lian, T. J. Phys. Chem. A 2000, 104, 4291

(39) Asbury, J. B.; Hao, E.; Wang, Y.; Ghosh, H. N.; Lian, T. J. Phys. Chem. B 2001, 105, 4545.

(40) Zaban, A.; Ferrere, S.; Sprague, J.; Gregg, B. A. J. Phys. Chem. B 1997, 101, 55

(41) Nutz, T.; Felde, U. Z.; Haase, M. J. Chem. Phys. 1999, 110, 12142.

(42) Anderson, N. A.; Ai, X.; Chen, D.; Mohler, D. L.; Lian, T. J. Phys. Chem. B 2003, 107, 14231 .

(43) Walters, K. A.; Gaal, D. A.; Hupp, J. T. J. Phys. Chem. B 2002 106,5139

(44) Yan, S. G.; Prieskorn, J. S.; Kim, Y.; Hupp, J. T. J. Phys. Chem. B 2000, 104, 10871 .

(45) Frisch, M. J.; Trucks, G. W.; Schlegel, H. B.; Scuseria, G. E.; Robb, M. A.; Cheeseman, J. R.; Montgomery Jr., J. A.; Vreven, T.; Kudin, K. N.; Burant, J. C.; Iyengar, S. S.; Millam, J. M.; Iyengar, S. S.; Tomasi, J.; Barone, V.; Mennucci, B.; Cossi, M.; Scalmani, G.; Rega, N.; Petersson, G. A.; Nakatsuji, H.; Hada, M.; Ehara, M.; Toyota, K.; Fukuda, R.; Hasegawa, J.; Ishida, M.; Nakajima, T.; Honda, Y.; Kitao, O.; Nakai, H.; M. Klene; Li, X.; Knox, J. E.; Hratchian, H. P.; Cross, J. B.; Bakken, V.; Adamo, C.; Jaramillo, J.; Gomperts, R.; Stratmann, R. E.; Vazyev, O.; Austin, A. J.; Cammi, R.; Pomelli, C.; Ochterski, J.; Ayala, P. Y.; Morokuma, K.; Voth, G. A.; Salvador, P.; Dannenberg, J. J.; Zakrzewski, V. G.; Dapprich, S.; Daniels, A. D.; Strain, M. C.; Farkas, O.; Malick, D. K.; Rabuck, A. D.; Raghavachari, K.; Foresman, J. B.; Ortiz, J. V.; Cui, Q.; Baboul, A. G.; Clifford, S.; Cioslowski, J.; Stefanov, B. B.; Liu, G.; Liashenko, A.; Piskorz, P.; Komaromi, I.; Martin, R. L.; Fox, D. J.; Keith, T.; Al-Laham, M. A.; Peng, C. Y.; Nanayakkara, A.; Challacombe, M.; Gill, P. M. W.; Johnson, B.; Chen, W.; Wong, M. W.; Gonzalez, C.; Pople, J. A. Gaussian 03, Revision D.1 ed.: Gaussian: Wallingford, CT, 2004

(46) Guo, J.; She, C.; Lian, T. J. Phys. Chem. B 2005, 109, 7095.

(47) Ai, X.; Guo, J.; Anderson, N. A.; Lian, T. J. Phys. Chem. B 2004, 108,12795 .

(48) Iwai, S.; Hara, K.; Murata, S.; Katoh, R.; Sugihara, H.; Arakawa, H. J. Chem. Phys. 2000, 113, 3366.

(49) Marcus, R. A. J. Chem. Phys. 1965, 43, 679.

(50) Gao, Y. Q.; Georgievskii, Y.; Marcus, R. A. J. Chem. Phys. 2000, 112,3358 .

(51) Gao, Y. Q.; Marcus, R. A. J. Chem. Phys. 2000, 113, 6351.

(52) Gosavi, S.; Marcus, R. A. J. Phys. Chem. B 2000, 104, 2067.

(53) Sauve, G.; Cass, M. E.; Doig, S. J.; Lauermann, I.; Pomykal, K.; Lewis, N. S. J. Phys. Chem. B 2000, 104, 3488.

(54) Redmond, G.; Fitzmaurice, D. J. Phys. Chem. 1993, 97, 1426. 